\title{
Using DHS and MICS data to complement or replace NGO \\ baseline health data: an exploratory study [version 1; peer
}

\section{review: 2 approved]}

\author{
Peter R. Berti (D1, Milena Nardocci(i)2, Minh Hung Tran³, Malek Batal2, \\ Rebecca Brodmann', Nicolas Greliche ${ }^{4}$, Naomi M. Saville 5 \\ ${ }^{1}$ HealthBridge Foundation of Canada, Ottawa, Canada \\ 2TRANSNUT, Université de Montréal, Montreal, Canada \\ ${ }^{3}$ Center for Creative Initiatives in Health and Population, Hanoi, Vietnam \\ ${ }^{4}$ Statistics for Sustainable Development, Reading, UK \\ 5 University College London Institute for Global Health, London, UK
}

V1 First published: 04 Feb 2021, 10:69

https://doi.org/10.12688/f1000research.47618.1

Latest published: 04 Feb 2021, 10:69

https://doi.org/10.12688/f1000research.47618.1

\section{Abstract}

Background: Non-government organizations (NGOs) spend substantial time and resources collecting baseline data in order to plan and implement health interventions with marginalized populations. Typically interviews with households, often mothers, take over an hour, placing a burden on the respondents. Meanwhile, estimates of numerous health and social indicators in many countries already exist in publicly available datasets, such as the Demographic and Health Surveys (DHS) and the Multiple Indicator Cluster Surveys (MICS), and it is worth considering whether these could serve as estimates of baseline conditions. The objective of this study was to compare indicator estimates from non-governmental organizations (NGO) health projects' baseline reports with estimates calculated using the Demographic and Health Surveys (DHS) or the Multiple Indicator Cluster Surveys (MICS), matching for location, year, and season of data collection.

Methods: We extracted estimates of 129 indicators from 46 NGO baseline reports, 25 DHS datasets and three MICS datasets, generating 1,996 pairs of matched DHS/MICS and NGO indicators. We subtracted NGO from DHS/MICS estimates to yield difference and absolute difference, exploring differences by indicator. We partitioned variance of the differences by geographical level, year, and season using ANOVA.

Results: Differences between NGO and DHS/MICS estimates were large for many indicators but 33\% fell within 5\% of one another. Differences were smaller for indicators with prevalence $<15 \%$ or $>85 \%$. Difference between estimates increased with increasing year and geographical level differences. However, $<1 \%$ of the variance of the

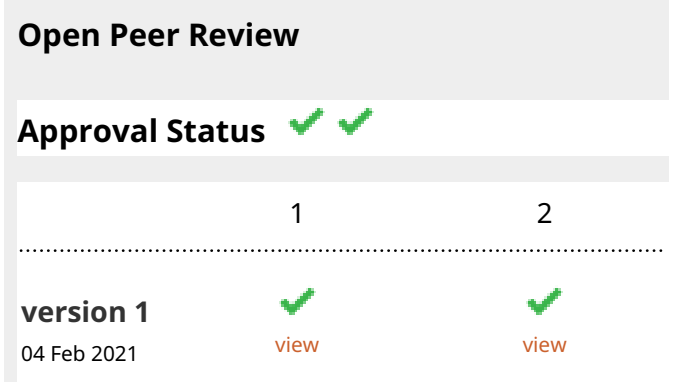

1. Luay Basil, Canadian Red Cross Society, Ottawa, Canada

2. Neff Walker, Johns Hopkins Bloomberg

School of Public Health, Baltimore, USA

Any reports and responses or comments on the article can be found at the end of the article. 
differences was explained by year, geographical level, and season.

Conclusions: There are situations where publicly available data could complement NGO baseline survey data, most importantly when the NGO has tolerance for estimates of low or unknown accuracy.

\section{Keywords}

DHS, MICS, surveys, maternal and child health

\section{Corresponding author: Peter R. Berti (pberti@healthbridge.ca)}

Author roles: Berti PR: Conceptualization, Data Curation, Formal Analysis, Funding Acquisition, Investigation, Methodology, Supervision, Validation, Visualization, Writing - Original Draft Preparation, Writing - Review \& Editing; Nardocci M: Data Curation, Formal Analysis, Investigation, Methodology, Validation, Visualization, Writing - Original Draft Preparation, Writing - Review \& Editing; Tran MH: Data Curation, Formal Analysis, Investigation, Visualization, Writing - Review \& Editing; Batal M: Conceptualization, Funding Acquisition, Methodology, Supervision, Validation, Writing - Review \& Editing; Brodmann R: Conceptualization, Funding Acquisition, Methodology, Project Administration, Writing - Review \& Editing; Greliche N: Formal Analysis, Methodology, Visualization, Writing Review \& Editing; Saville NM: Data Curation, Formal Analysis, Investigation, Methodology, Writing - Review \& Editing

Competing interests: No competing interests were disclosed.

Grant information: This project is brought to you in partnership with Global Affairs Canada and the Canadian partnership for Women and Children's Health (CanWaCH).

The funders had no role in study design, data collection and analysis, decision to publish, or preparation of the manuscript.

Copyright: @ 2021 Berti PR et al. This is an open access article distributed under the terms of the Creative Commons Attribution License, which permits unrestricted use, distribution, and reproduction in any medium, provided the original work is properly cited.

How to cite this article: Berti PR, Nardocci M, Tran MH et al. Using DHS and MICS data to complement or replace NGO baseline health data: an exploratory study [version 1; peer review: 2 approved] F1000Research 2021, 10:69

https://doi.org/10.12688/f1000research.47618.1

First published: 04 Feb 2021, 10:69 https://doi.org/10.12688/f1000research.47618.1 


\section{Introduction}

Non-government and civil society organizations spend substantial time and resources collecting baseline data in order to plan and implement health interventions with marginalized populations, and to measure the impact of those interventions (Data for Impact, 2019). Typical methods involve baseline and endline household surveys, where the household residents are interviewed and asked a hundred or more questions about asset ownership, mother and child health, diet, health system access, and other topics of interest. The costs of these surveys vary depending on design, methods, sample size, survey length, and local context (Data for Impact, 2019), but in the authors' experience tens of thousands of dollars is typical, and in some cases, much more. Depending on the number and nature of questions, interviews can be over an hour long, placing a burden on the respondents. In addition, the accuracy of the indicator estimates in NGO-led surveys may be insufficient for project design and monitoring purposes, due to relatively small sample sizes and the inherent high variability of the indicators of interest.

Meanwhile, estimates of numerous health and social indicators in many countries already exist in publicly available datasets, such as the Demographic and Health Surveys (DHS), supported by USAID (U.S. Agency for International Development, 2018), and the Multiple Indicator Cluster Surveys (MICS), supported by UNICEF (UNICEF, 2020), and it is worth considering whether these could serve as estimates of baseline conditions. DHS/MICS provide standardized data collected using rigorous methods and large sample sizes, and datasets are available on request for free. They are designed to be representative at the national, regional and provincial level (but rarely at lower levels, such as district and village, where NGOs are working), and probably exclude homeless, institutionalized and nomadic populations (Carr-Hill, 2013). DHS/MICS are collected every three to ten years so there may up to ten-years gap between DHS/MICS data collection and the baseline conditions that the NGO wants characterized. Although some indicators' descriptions have been modified and improved over time, caution is taken to ensure that data are directly comparable across countries, regions and years (Hancioglu \& Arnold, 2013; UNICEF, 2020; U.S. Agency for International Development, 2018). DHS/MICS surveys are adapted to specific country needs and are conducted by well-trained interviewers who have access to tools and guidelines for quality assurance throughout (UNICEF, 2020; U.S. Agency for International Development, 2018).

Using publicly available data to complement or replace NGOs' primary data collection for project baseline measures and project monitoring would save valuable resources, reducing the burden on data collectors and respondents alike. A few studies have compared estimates between DHS/MICS and NGO surveys. One found that they provided very different estimates of electricity and water access in Kenya, Tanzania, and Uganda (Carr-Hill, 2017), and a second found that DHS and a NGO-led survey provided similar estimates of several maternal and child health estimates in Rwanda (Langston et al., 2015). Other studies found that estimates of the market share of faith-based health care providers by DHS and NGO surveys in sub-Saharan Africa were within 5 to $50 \%$ of each other (Wodon et al., 2012), and the confidence intervals for the difference between Lot Quality Assurance Sampling (LQAS) and DHS district-level estimates were within $+/-10 \%$ for 15 of 37 health indicators (Anoke et al., 2015). Therefore, no consensus exists on the potential for DHS/MICS to substitute NGO surveys.

We hypothesized that publicly available data can provide estimates of baseline conditions similar to those reported in NGO baseline reports when matched as closely as possible for location, year, and season of data collection. We tested this hypothesis by comparing indicator estimates from NGO reports with estimates calculated using DHS/MICS.

\section{Methods}

Data from NGO baseline reports

We collected and retained a sample of 46 NGO baseline reports through a combination of internet search and personal contacts with Canadian and Vietnamese NGOs using the following selection criteria:

i) household survey $(n>100)$ which used valid methods and representative sampling to generate point estimates of maternal, newborn and child health indicators;

ii) conduced between 2005 and 2019;

iii) in a low- or middle-income country.

The baseline reports from NGOs working on maternal, newborn and child health covered 23 countries spanning South Asia (Bangladesh, India, Pakistan), Africa (Burkina Faso, Ethiopia, Ghana, Kenya, Liberia, Malawi, Mali, Mozambique, Nigeria, Senegal, South Sudan, Tanzania, Zambia), South/Central America (Bolivia, Honduras), the Caribbean (Haiti), and SE Asia (Laos, Myanmar, Philippines, Vietnam) (Table 1) (Berti, 2021). From the reports, we extracted: country name, NGO name, dates of data collection, population of study, inclusion/exclusion criteria, indicator 


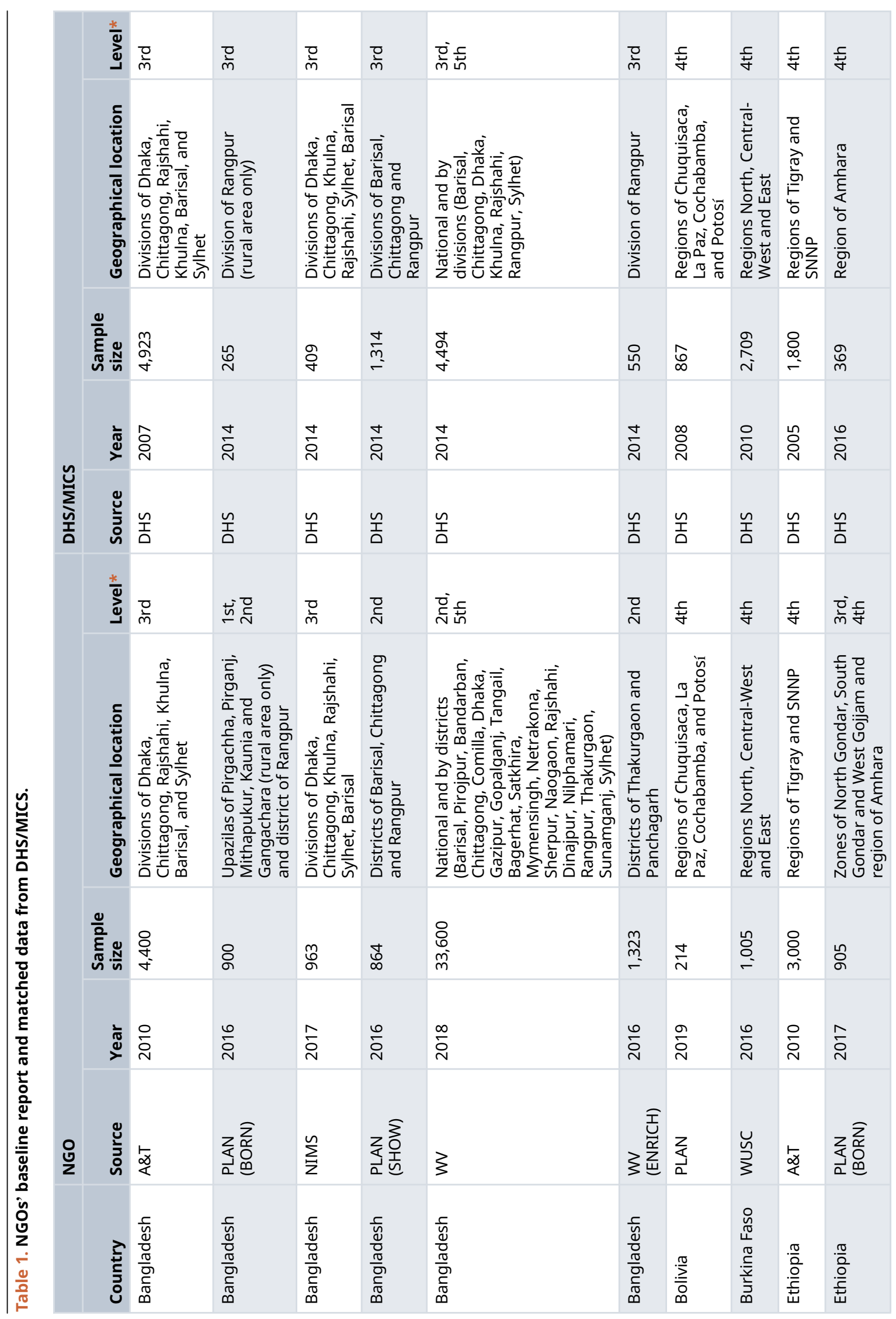




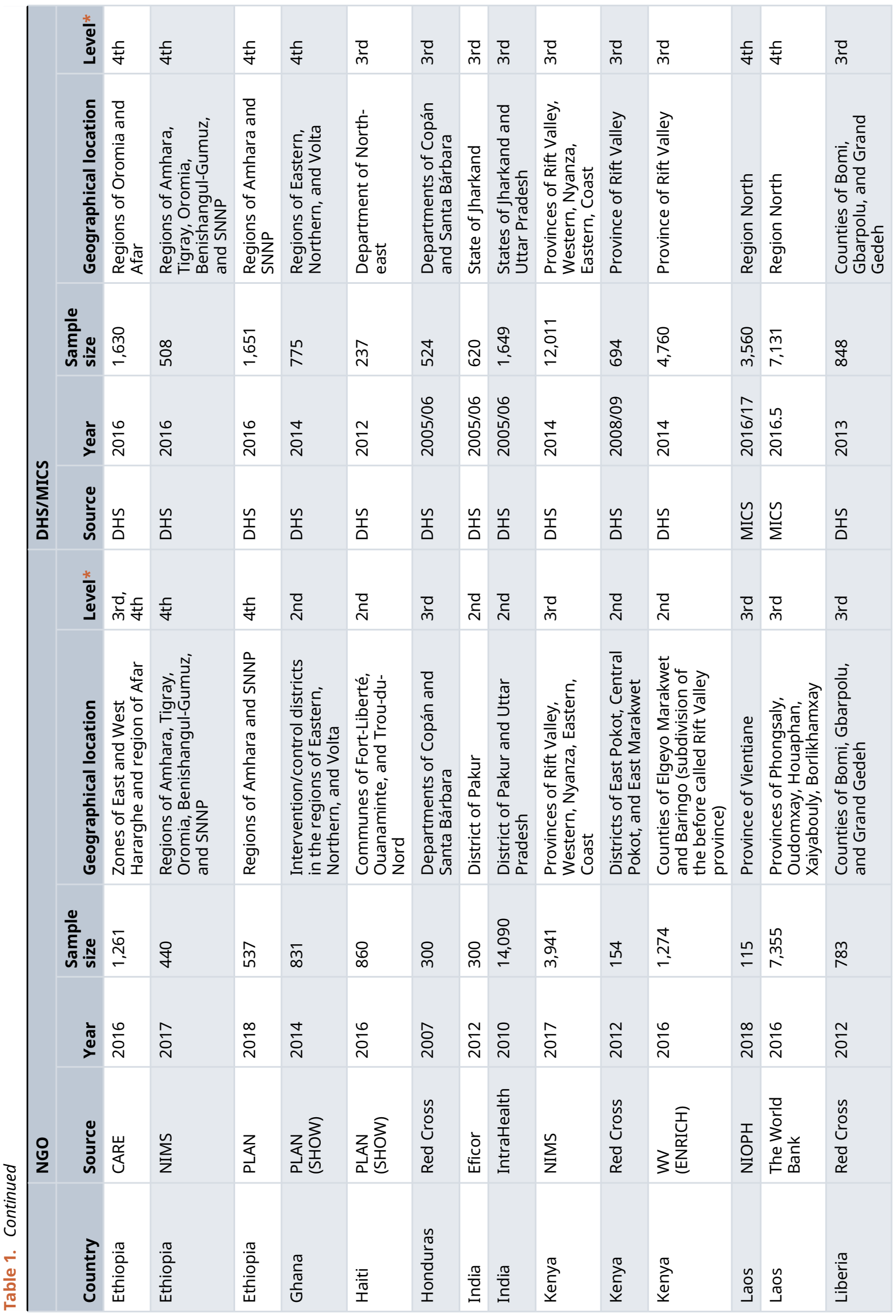




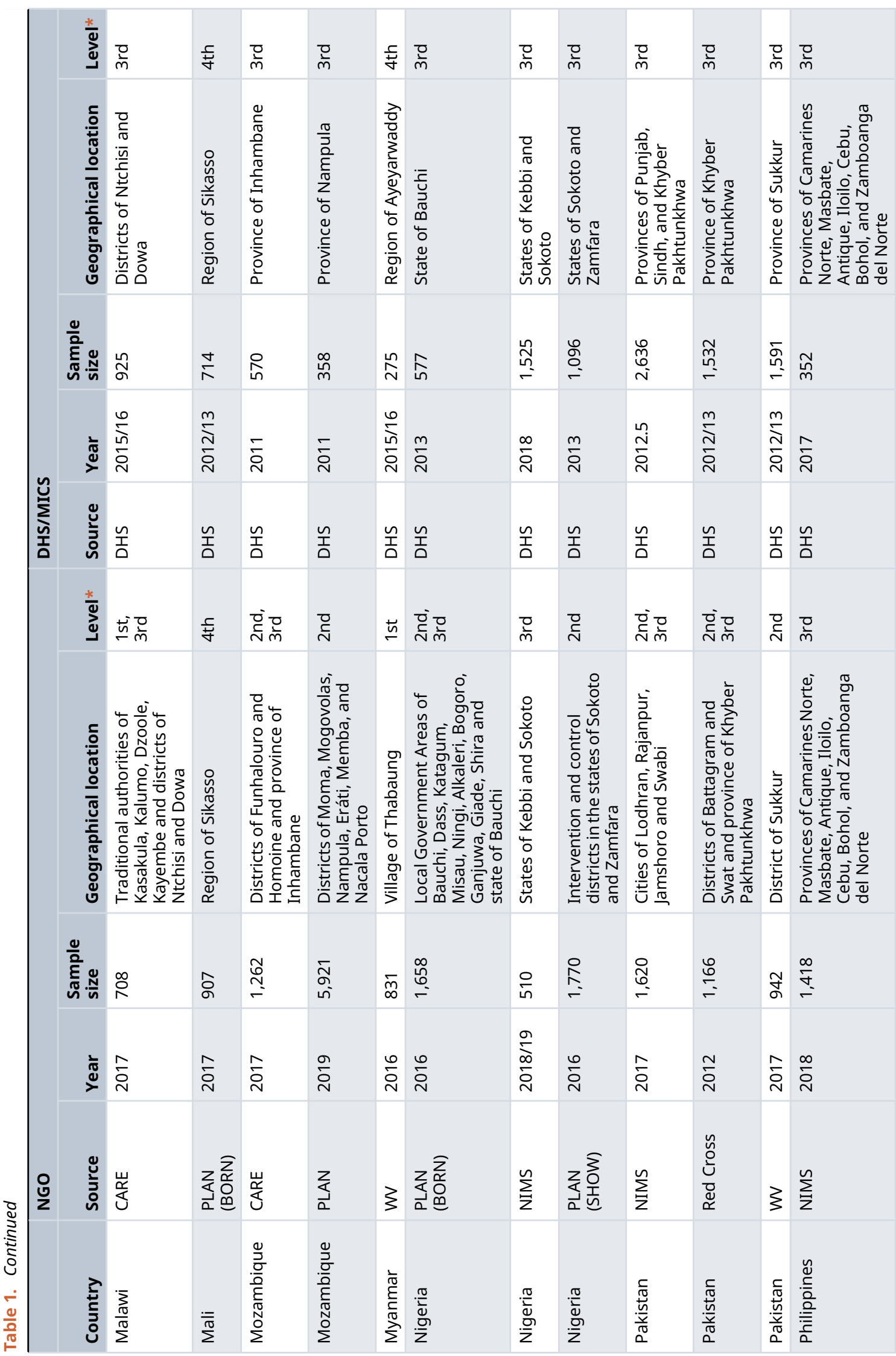




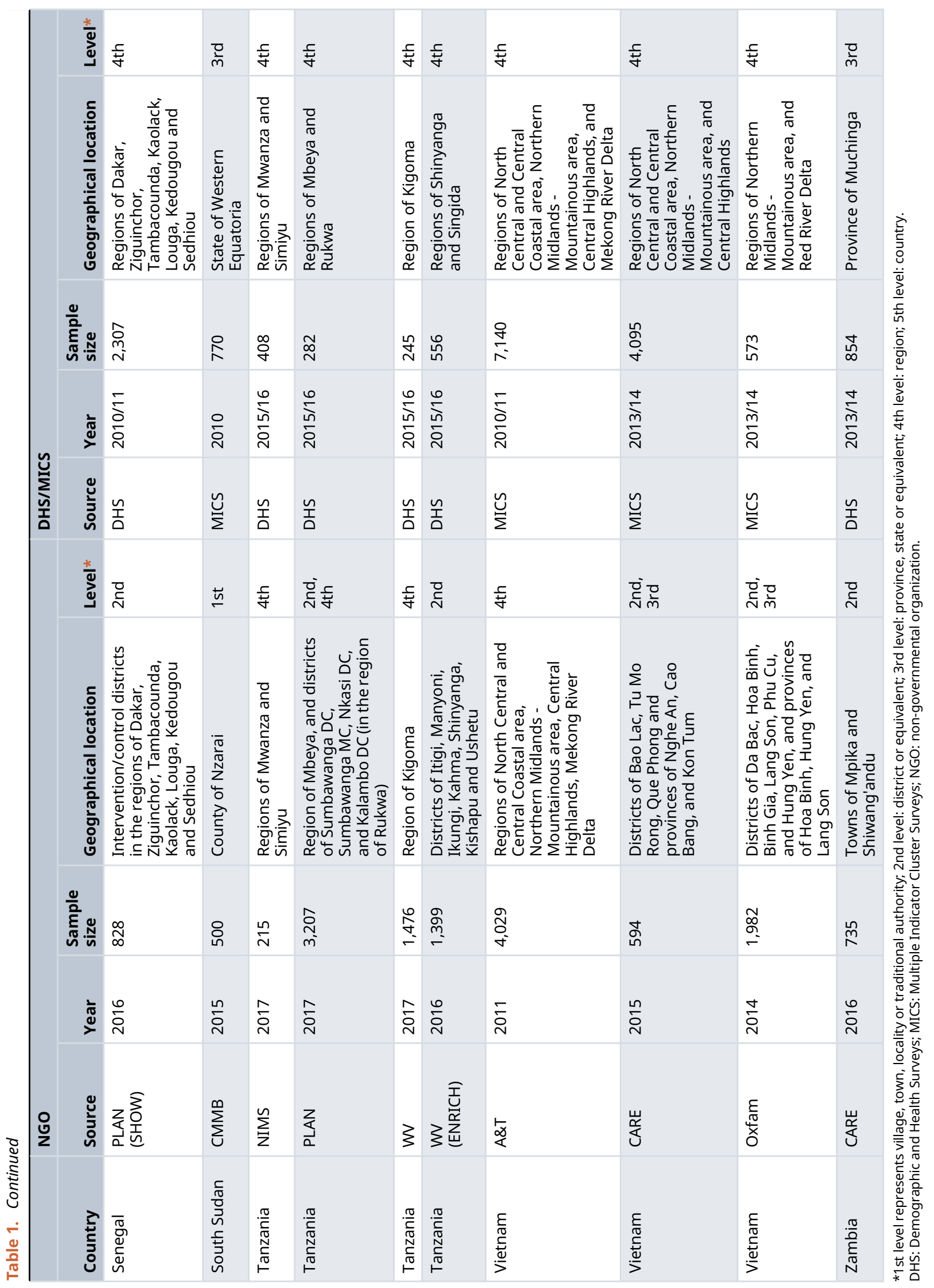


name and definition, sample size (total and $n$ for each indicator), and the indicator estimate (percentage and standard deviation (SD) if available).

We also retained the location of data collection (e.g. country, region, province, district, or/and village) and geographical level. These geographical levels of data aggregation were defined as: (1) the smallest geographical subdivision in a country (village, town, locality, traditional authority); (2) district or district council (larger than a village but smaller than the third level); (3) province, state, department, county or district (if it refers to a division equivalent to province or state); (4) region (combining several units of level 3); (5) country level.

\section{Data from DHS and MICS surveys}

We matched 25 DHS and 3 MICS surveys (from Vietnam, Laos, and South Sudan) with 46 NGO baseline reports (Table 1). We used the most recent DHS/MICS survey carried out prior to the NGO baseline survey, with some surveys matching more than one NGO survey.

Indicators from DHS/MICS were calculated following the methods recommended by DHS/MICS accounting for weighting and sample selection (Croft et al., 2018). Wherever possible, we used the methods employed by the NGO to create the matching DHS/MICS indicator. For instance, if the NGO baseline survey included women of reproductive age and their children aged 0-24 months living in the district of Homoine in Mozambique, we extracted the same sample from the DHS/MICS. In the absence of representative data from the same geographical level, we used DHS/MICS data from the next level up in the geopolitical hierarchy to match the lower level from the NGO. For instance, if data from the district of Homoine were not available in the DHS, we used data from the province of Inhambane (one level up).

\section{Indicators retained for analysis}

We matched similar indicators from NGO baseline reports with DHS/MICS wherever available and excluded those that had no match in the DHS/MICS datasets. Table 2 provides an example of how the data were matched for the indicator "Woman received at least three antenatal care visits (ANC) during last pregnancy".

In total there were 129 indicators (Table 3) from eight main groups including child anthropometry, child diet, child health, household characteristics, household wealth, maternal characteristics, maternal health, and WASH. We excluded estimates based on fewer than ten observations $(n=64)$, in either the DHS/MICS or NGO data, retaining a total of 1,996 pairs of NGO-DHS/MICS indicators for analyses.

After collating the data, we grouped similar indicators into 37 subgroups (Table 3) on the basis of whether they had similar definitions/concepts (e.g. stunting prevalence in different age groups). We refined the grouping by using scatterplots of the difference of estimates by year difference and geographical level difference to check if any indicators differed widely from others in the grouping. After assessing the indicators graphically, we separated "Diarrhea in the last two weeks: $0-5 \mathrm{~m}$ " from the same indicator for other age groups since the differences of estimates were closer to zero for this age group than the others. We also separated "Household has a car" from the subgroup "Household has agricultural land/bike/ phone" since car ownership was much lower than ownership of other assets.

\section{Analysis}

NGO versus DHS/MICS

We subtracted NGO from DHS/MICS estimates to calculate difference and absolute difference between estimates.

To compare data from NGO and DHS/MICS we used: same or different season of data collection; number of years difference between data collection (DHS/MICS year - NGO year); and number of geographical levels difference (DHS/MICS level - NGO level). If data collection spanned two years, for instance data collection started in 2013 and was completed in 2014 , the year of data collection was coded as "2013.5". Geographical level difference was calculated by subtracting the NGO level from DHS/MICS level. For example, we subtracted district level data available from the Mozambique NGO survey (level=2) from province level data collected in the DHS (level=3), making the geographical level difference one. We grouped geographical level differences as: no difference; one level difference; 2-3 levels difference.

We plotted how difference and absolute difference between DHS/MICS and NGO estimates varied with the indicator and indicator grouping. We used Analysis of Variance (ANOVA) to partition the variance of difference or absolute difference between estimates (DHS/MICS estimate - NGO estimate) by indicator, geographical level difference (as 0,1,2+), year difference (continuous), and season (same season, different season, season unknown). 


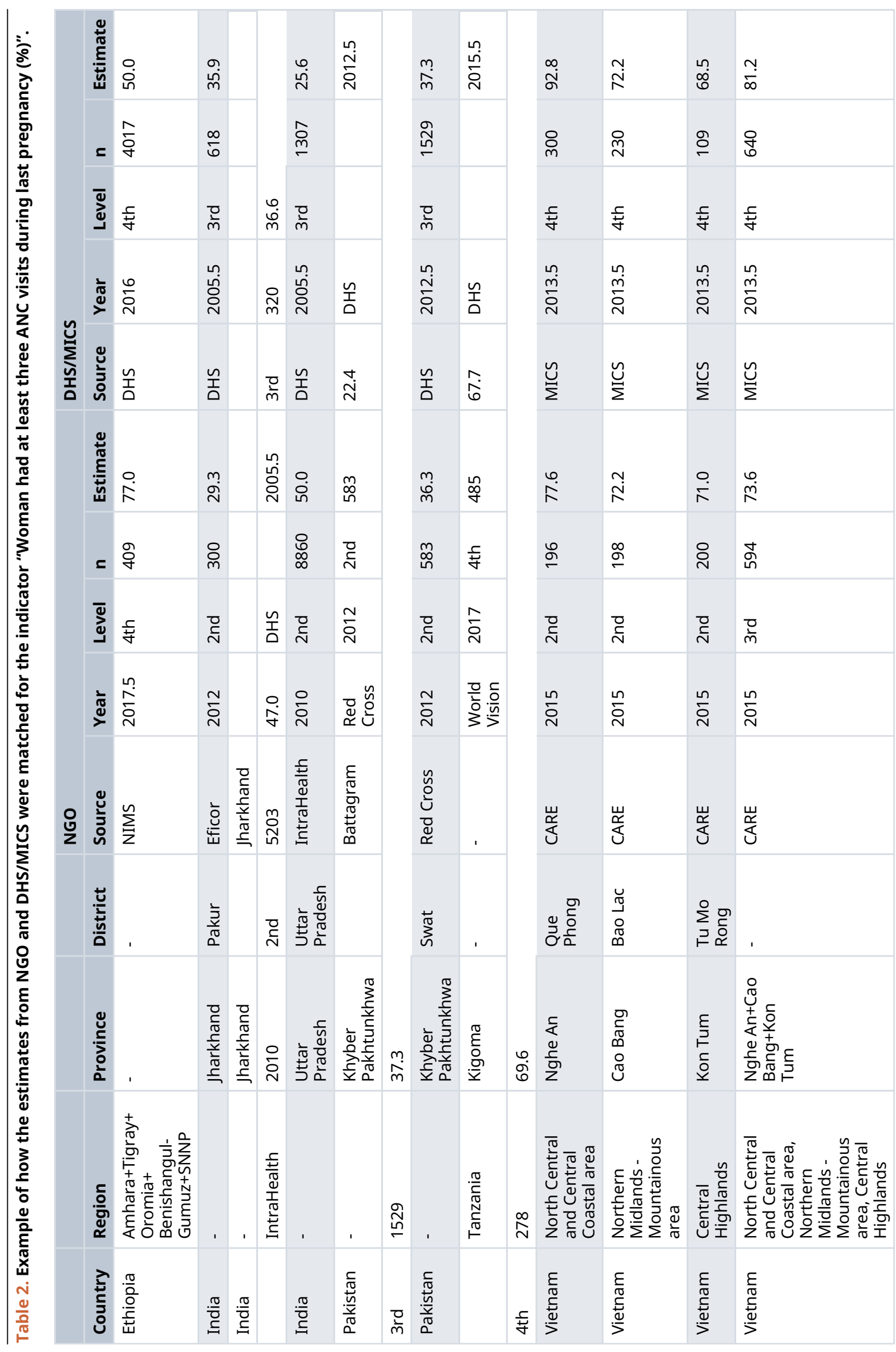




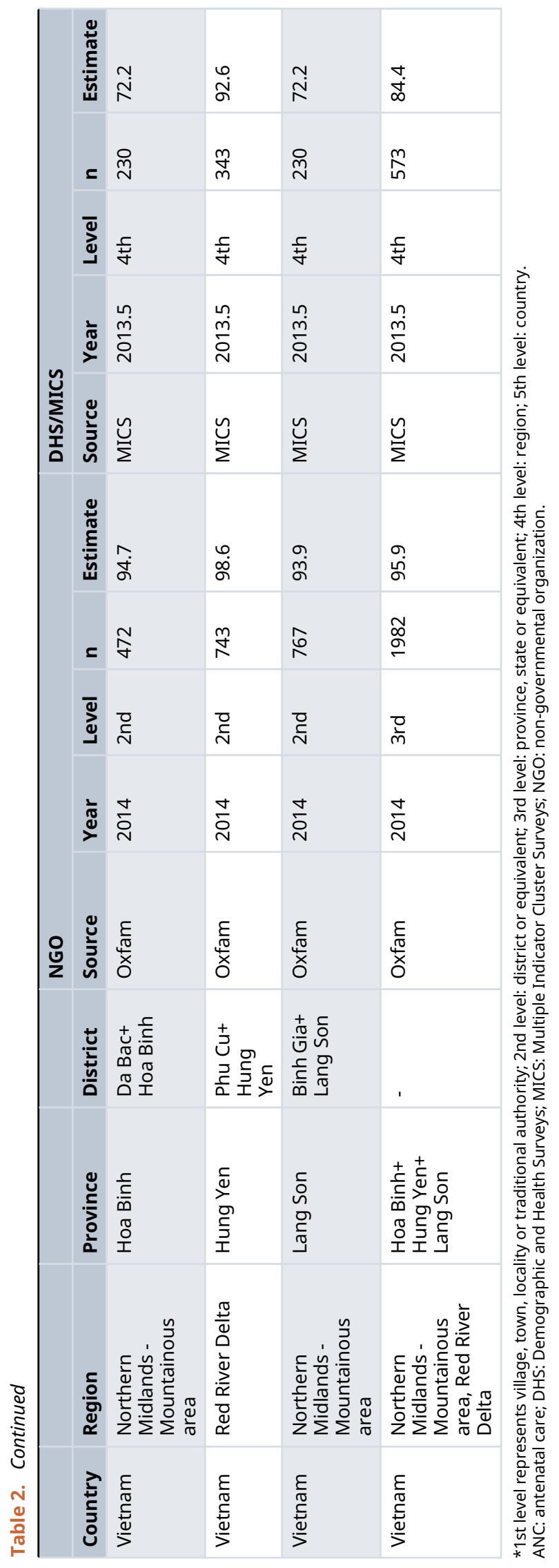




\section{Table 3. List of indicators collected by group and subgroup*}

\begin{tabular}{|c|c|c|c|}
\hline Group & Subgroup & $\begin{array}{l}\mathbf{N} \\
\text { indicators } \\
\text { in } \\
\text { subgroup }\end{array}$ & Details \\
\hline $\begin{array}{l}\text { Child } \\
\text { anthropometry }\end{array}$ & Stunting & 19 & $\begin{array}{l}\text { There are separate indicators by age groups, } \\
\text { and for boys and girls (separated and } \\
\text { combined) }\end{array}$ \\
\hline $\begin{array}{l}\text { Child } \\
\text { anthropometry }\end{array}$ & Underweight & 22 & $\begin{array}{l}\text { There are separate indicators by age groups, } \\
\text { and for boys and girls (separated and } \\
\text { combined) }\end{array}$ \\
\hline Child diet & Ate $4+$ food groups & 5 & $\begin{array}{l}\text { By age group and by breastfeeding status, and } \\
\text { combined }\end{array}$ \\
\hline Child diet & Bottle fed yesterday & 3 & By age group, and combined \\
\hline Child diet & Consumed iron-rich foods & 4 & By age group, and combined \\
\hline Child diet & $\begin{array}{l}\text { Consumed vitamin A-rich } \\
\text { foods }\end{array}$ & 1 & \\
\hline Child diet & Continued breastfeeding & 4 & By age group \\
\hline Child diet & $\begin{array}{l}\text { Exclusive breastfeeding: } \\
0-6 \mathrm{~m}\end{array}$ & 3 & Boys and girls separately and combined \\
\hline Child diet & $\begin{array}{l}\text { Initiation of breastfeeding } \\
\text { within } 1 \text { hour of birth }\end{array}$ & 3 & Boys and girls separately and combined \\
\hline Child diet & $\begin{array}{l}\text { Receiving solid, semi-solid } \\
\text { or soft foods: } 6-8 \mathrm{~m}\end{array}$ & 1 & \\
\hline Child health & $\begin{array}{l}\text { Child took supplement/ } \\
\text { vaccine }\end{array}$ & 4 & $\begin{array}{l}\text { Child received iron or vitamin A supplements, } \\
\text { child received DPT and measles by } 12 \text { months } \\
\text { of age, newborn protected by tetanus vaccine }\end{array}$ \\
\hline Child health & Diarrhea in last two weeks & 6 & $\begin{array}{l}\text { By age group (diarrhea in } 0-5 \mathrm{~m} \text { is separate } \\
\text { subgroup) }\end{array}$ \\
\hline Child health & $\begin{array}{l}\text { Diarrhea in the last two } \\
\text { weeks: } 0-5 \mathrm{~m}\end{array}$ & 1 & \\
\hline Child health & $\begin{array}{l}\text { Received diarrhea } \\
\text { treatment }\end{array}$ & 4 & $\begin{array}{l}\text { Those with diarrhea received ORS, ORT, } \\
\text { homemade fluids, ORS+ zinc }\end{array}$ \\
\hline Child health & $\begin{array}{l}\text { For those with diarrhea in } \\
\text { last } 2 \text { weeks, given more to } \\
\text { drink }\end{array}$ & 1 & \\
\hline Child health & $\begin{array}{l}\text { For those with diarrhea in } \\
\text { last } 2 \text { weeks, given more to } \\
\text { eat }\end{array}$ & 1 & \\
\hline $\begin{array}{l}\mathrm{HH} \\
\text { characteristics }\end{array}$ & $\begin{array}{l}\text { Individuals who have ever } \\
\text { been married }\end{array}$ & 1 & \\
\hline $\begin{array}{l}\mathrm{HH} \\
\text { characteristics }\end{array}$ & Head of household is male & 1 & \\
\hline $\begin{array}{l}\mathrm{HH} \\
\text { characteristics }\end{array}$ & Household has electricity & 1 & \\
\hline $\begin{array}{l}\mathrm{HH} \\
\text { characteristics }\end{array}$ & Urban residence & 1 & \\
\hline $\mathrm{HH}$ wealth & Household has a car & & \\
\hline HH wealth & $\begin{array}{l}\text { Household has agricultural } \\
\text { land/bike/phone }\end{array}$ & 3 & Household has land, bike, phone \\
\hline $\mathrm{HH}$ wealth & Household has animals & 6 & $\begin{array}{l}\text { Household has cattle, chickens, goats, horses, } \\
\text { livestock, poultry, sheep }\end{array}$ \\
\hline $\begin{array}{l}\text { Maternal } \\
\text { characteristics }\end{array}$ & Woman able to read & 1 & \\
\hline
\end{tabular}


Table 3. Continued

\begin{tabular}{|c|c|c|c|}
\hline Group & Subgroup & $\begin{array}{l}\mathrm{N} \\
\text { indicators } \\
\text { in } \\
\text { subgroup }\end{array}$ & Details \\
\hline $\begin{array}{l}\text { Maternal } \\
\text { characteristics }\end{array}$ & $\begin{array}{l}\text { Woman never attended } \\
\text { school }\end{array}$ & 1 & \\
\hline $\begin{array}{l}\text { Maternal } \\
\text { health }\end{array}$ & $\begin{array}{l}\text { Birth at a health facility/ } \\
\text { assisted by a skilled birth } \\
\text { attendant (SBA) }\end{array}$ & 3 & $\begin{array}{l}\text { Last birth at health facility, attended by SBA, } \\
\text { assisted by SBA }\end{array}$ \\
\hline $\begin{array}{l}\text { Maternal } \\
\text { health }\end{array}$ & $\begin{array}{l}\text { Woman consumed/ } \\
\text { received iron supplements }\end{array}$ & 5 & $\begin{array}{l}\text { Woman received iron supplements, woman } \\
\text { consumed iron supplements on } 1+, 90+, 100+\text {, } \\
150+\text { days }\end{array}$ \\
\hline $\begin{array}{l}\text { Maternal } \\
\text { health }\end{array}$ & $\begin{array}{l}\text { Woman received antenatal } \\
\text { care (ANC) }\end{array}$ & 4 & $\begin{array}{l}\text { In last pregnancy, woman had ANC in first } \\
\text { trimester, woman had } 1+, 3+, 4+\text { ANC visits }\end{array}$ \\
\hline $\begin{array}{l}\text { Maternal } \\
\text { health }\end{array}$ & $\begin{array}{l}\text { Woman received postnatal } \\
\text { care (PNC) }\end{array}$ & 3 & $\begin{array}{l}\text { Woman received PNC, Woman received PNC } \\
\text { with } 2 \text { days } / 3 \text { days of birth }\end{array}$ \\
\hline $\begin{array}{l}\text { Maternal } \\
\text { health }\end{array}$ & $\begin{array}{l}\text { Woman's antenatal care } \\
\text { (ANC) content }\end{array}$ & 5 & $\begin{array}{l}\text { During ANC woman had blood/urine test, } \\
\text { blood pressure taken, received } 2+\text { TT vaccines, } \\
\text { was weighed. }\end{array}$ \\
\hline WASH & $\begin{array}{l}\text { Handwash station has } \\
\text { ash/sand/soap/water }\end{array}$ & 3 & $\begin{array}{l}\text { Household handwash station has ash/sand, } \\
\text { water, soap }\end{array}$ \\
\hline WASH & $\begin{array}{l}\text { Household dispose child } \\
\text { stool in toilet/latrine }\end{array}$ & 1 & \\
\hline WASH & $\begin{array}{l}\text { Household has improved } \\
\text { drinking water }\end{array}$ & 1 & \\
\hline WASH & $\begin{array}{l}\text { Household has improved } \\
\text { sanitation }\end{array}$ & 1 & \\
\hline WASH & Household shares toilet & 1 & \\
\hline WASH & $\begin{array}{l}\text { Household treats drinking } \\
\text { water }\end{array}$ & 2 & Household bleaches/boils drinking water \\
\hline WASH & $\begin{array}{l}30+\min \text { for household to } \\
\text { obtain drinking water }\end{array}$ & 1 & \\
\hline
\end{tabular}

*for a complete list of all the indicators see Table 2 in HealthBridge (2020).

HH: household; WASH: Water, Sanitation, and Hygiene; DPT: diphtheria, pertussis and tetanus; ORS: oral rehydration salts; ORT: oral rehydration therapy; SBA: skilled birth attendant; ANC: antenatal care; PNC: postnatal care; TT: tetanus toxoid.

\section{DHS versus DHS}

In order to better understand the contribution of difference in methods employed in the different sources of survey data (DHS/MICS and NGO) to the resulting difference in estimates, we repeated the analyses used to compare DHS/MICS and NGO estimates but this time comparing DHS data from one country, year and geographical level to a different year and/or geographical level from the same country. The assumption is that the DHS methods are similar between years and geographical levels, whereas DHS/MICS and NGOs may use somewhat different methods. There is a level of discordance between DHS/MICS and NGO estimates, and there would also be discordance between two DHS estimates. The difference between DHS/MICS-NGO discordance and DHS-DHS discordance will not be due to difference in years, or geographical levels, but rather due to difference in methods.

For the DHS-DHS comparisons, we compiled DHS data from the seven countries that contributed the most pairs in the DHS/MICS-NGO dataset: Bangladesh, Ethiopia, Kenya, Malawi, Pakistan, Tanzania, and Zambia. Retaining the same indicators as in the DHS/MICS - NGO comparisons, we calculated estimates for different geographical levels, i.e. at the country level, and for each region, province and district available. For this analysis, we included district data to mimic the NGO data, even though these estimates are not always representative at this level in the DHS. We excluded indicators based on a sample size smaller than ten observations $(n=26,539)$.

We matched DHS indicators from different cycles and geographical levels using different combinations mimicking the actual DHS/MICS-NGO scenarios: indicators from the same level but different years (Scenario 1), indicators from the 


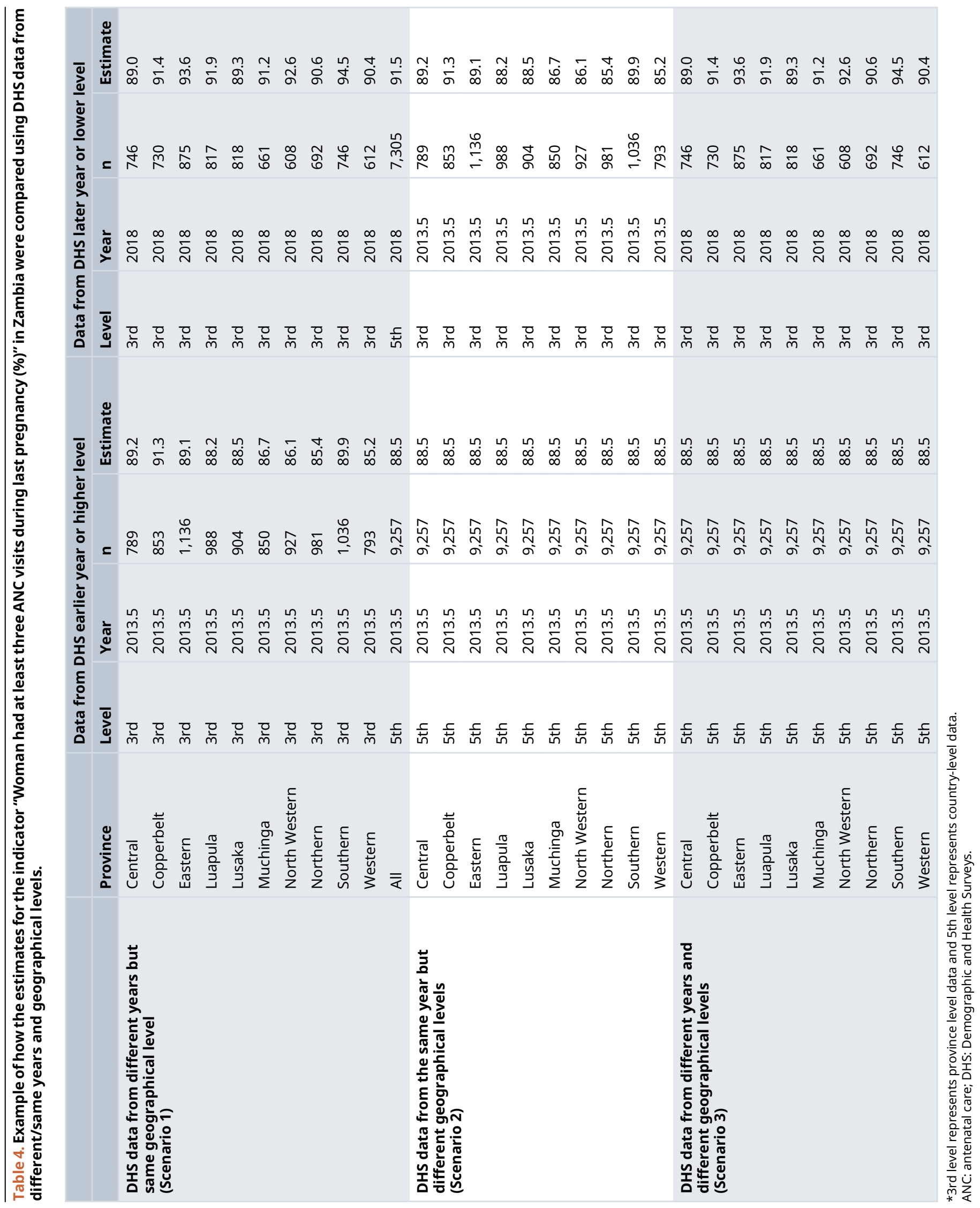


same year but different levels (Scenario 2), and indicators from different years and levels (Scenario 3). To mimic the NGO data, we used data from the most recent cycle and the lower geographical levels, whereas to represent the comparative DHS data we used older DHS cycle and higher geographical level data. Using DHS data only, we were not able to simulate a scenario where DHS/MICS and NGO data were from the same year and geographical level. Table 4 provides an example of how we compared the estimates for an ANC indicator in Zambia using 31 pairs from DHS in the three scenarios for this one country. Repeating across all indicators and all countries yielded 109,251 pairs of DHS-DHS indicators.

We calculated the difference and absolute difference between these pairs of estimates, mimicking the scenarios from the DHS/MICS-NGO data. Table 5 summarises the DHS cycles included as well as the geographical level comparison for each scenario in each of the seven countries.

Finally, as with DHS/MICS vs NGO estimates, we used ANOVA to partition the variance of difference or absolute difference between DHS estimates by indicator, geographical level difference, and year difference. We did not include season in this analysis since most DHS data are collected during the same season within a country.

\section{Simulations}

We simulated a situation where the only source of imprecision of the indicator's measures would be from sampling error, in order to separate this known and estimable source of error from other sources of error that lead to differences in indicator estimates. The simulation samples from a "true" prevalence (p) of 1\%, 10\%, 20\%, 30\%, 40\%, 50\%, 60\%, $70 \%, 80 \%, 90 \%$, and $99 \%$. We assumed an $\mathrm{n}$ of 500, which was a typical sample size of both DHS and NGO samples in our data set. We then generated a "Baseline Estimate 1" (to mimic the DHS/MICS estimates) by drawing randomly from a binomial distribution with mean $n^{*} p$ and variance $n p(1-p)$. A "Baseline estimate 2" (to mimic the NGO estimate) was generated in the same way, and the difference between the first and second estimate was calculated. We ran 1,000 iterations to estimate the distribution of the differences.

In order to investigate how absolute differences vary by the nature of the point prevalence estimates we used box plots to compare simulated, DHS-DHS and DHS/MICS-NGO absolute differences.

Table 5. Demographic and Health Survey (DHS) cycles and geographical level comparison included in the DHS vs DHS analysis.

\begin{tabular}{|c|c|c|c|c|c|c|}
\hline \multirow[b]{2}{*}{ Country } & \multicolumn{2}{|c|}{ Scenario $1(N=9,024)$} & \multicolumn{2}{|c|}{ Scenario $2(N=56,185)$} & \multicolumn{2}{|c|}{ Scenario $3(\mathrm{~N}=44,042)$} \\
\hline & $\begin{array}{l}\text { DHS } \\
\text { cycle }\end{array}$ & $\begin{array}{l}\text { Geographical } \\
\text { level comparison }\end{array}$ & $\begin{array}{l}\text { DHS } \\
\text { cycle }\end{array}$ & $\begin{array}{l}\text { Geographical } \\
\text { level comparison }\end{array}$ & $\begin{array}{l}\text { DHS } \\
\text { cycle }\end{array}$ & $\begin{array}{l}\text { Geographical } \\
\text { level comparison }\end{array}$ \\
\hline Bangladesh & $\begin{array}{l}2011 \\
2014\end{array}$ & $\begin{array}{l}\text { 3rd-3rd } \\
\text { 5th-5th }\end{array}$ & 2014 & $\begin{array}{l}\text { 3rd-2nd } \\
\text { 5th-2nd } \\
\text { 5th-3rd }\end{array}$ & $\begin{array}{l}2011 \\
2014\end{array}$ & $\begin{array}{l}\text { 3rd-2nd } \\
\text { 5th-2nd } \\
\text { 5th-3rd }\end{array}$ \\
\hline Ethiopia & $\begin{array}{l}2011 \\
2016\end{array}$ & $\begin{array}{l}\text { 3rd-3rd } \\
\text { 5th-5th }\end{array}$ & 2016 & 5th-3rd & $\begin{array}{l}2011 \\
2016\end{array}$ & 5 th-3rd \\
\hline Kenya & $\begin{array}{l}2008.5 \\
2014\end{array}$ & $\begin{array}{l}\text { 3rd-3rd } \\
\text { 5th-5th }\end{array}$ & 2014 & 5th-3rd & $\begin{array}{l}2008.5 \\
2014\end{array}$ & 5th-3rd \\
\hline Malawi & $\begin{array}{l}2010 \\
2015.5\end{array}$ & $\begin{array}{l}\text { 3rd-3rd } \\
\text { 4th-4th } \\
\text { 5th-5th }\end{array}$ & 2015.5 & $\begin{array}{l}\text { 4th-3rd } \\
\text { 5th-3rd } \\
\text { 5th-4th }\end{array}$ & $\begin{array}{l}2010 \\
2015.5\end{array}$ & $\begin{array}{l}\text { 4th-3rd } \\
\text { 5th-3rd } \\
\text { 5th-4th }\end{array}$ \\
\hline Pakistan & $\begin{array}{l}2006.5 \\
2012.5\end{array}$ & $\begin{array}{l}\text { 3rd-3rd } \\
\text { 5th-5th }\end{array}$ & 2012.5 & $\begin{array}{l}\text { 3rd-2nd } \\
\text { 5th-2nd } \\
\text { 5th-3rd }\end{array}$ & $\begin{array}{l}2006.5 \\
2012.5\end{array}$ & $\begin{array}{l}\text { 3rd-2nd } \\
5 \text { th-2nd } \\
\text { 5th-3rd }\end{array}$ \\
\hline Tanzania & $\begin{array}{l}2010 \\
2015.5\end{array}$ & $\begin{array}{l}\text { 4th-4th } \\
\text { 5th-5th }\end{array}$ & 2015.5 & $\begin{array}{l}\text { 4th-2nd } \\
\text { 5th-2nd } \\
5 \text { th-4th }\end{array}$ & $\begin{array}{l}2010 \\
2015.5\end{array}$ & $\begin{array}{l}\text { 4th-2nd } \\
\text { 5th-2nd } \\
5 \text { th-4th }\end{array}$ \\
\hline Zambia & $\begin{array}{l}2013.5 \\
2018\end{array}$ & $\begin{array}{l}\text { 3rd-3rd } \\
\text { 5th-5th }\end{array}$ & 2013.5 & 5th-3rd & $\begin{array}{l}2013.5 \\
2018\end{array}$ & 5th-3rd \\
\hline
\end{tabular}

Geographical level comparison: geographical level from older cycle vs geographical level from most recent cycle included.2nd level represents district or equivalent; 3rd level: province, state or equivalent; 4th level: region; 5th level: country.

Scenario 1: DHS data from different years compared using the same geographical levels.Scenario 2: DHS data from the same year compared using different geographical levels.Scenario 3: DHS data from different years compared using different geographical levels. 
All data were compiled in Microsoft Excel 15 and analyzed with SAS 9.4.

This study respects current research ethics standards and it was approved by the Health Research Ethics Board of the Université de Montréal (CERSES-19-030-D).

\section{Results}

The NGO reports often presented over 100 indicators in their baseline reports. On average, 18 of their indicators were also available in the DHS/MICS datasets. The estimate sample size for the NGO surveys ranged from 12 to 16,530 and from 10 to 98,446 for the DHS/MICS. Table 6 presents, by indicator subgroup, mean DHS/MICS and NGO percentage prevalence estimates, mean difference between pairs (DHS/MICS minus NGO) and percentage of differences falling within 5 and 20 percentage points. Some subgroups have mean difference close to zero, but almost all have at least some pairs that are widely different (not within 20\%). Fifteen subgroups had positive (DHS $<$ NGO) and 21 had negative (DHS $>$ NGO) mean differences, but we identified no meaningful pattern in which indicators were negative and which were positive, and all the differences (except for consumption of vitamin A-rich foods) were within 1 standard deviation of 0 .

Figure 1 presents the scatterplots of NGO against DHS/MICS estimates by subgroup of indicators. For all subgroups, there was some correlation between the DHS/MICS and NGO estimates. Figure 2 shows the boxplot distribution of the mean difference between estimates by subgroup. The only subgroups that had all the pairs of indicators within $\pm 20 \%$ were "Consumption of vitamin A-rich foods", "Bottle fed yesterday", "Diarrhea in the last two weeks: 0-5m", "Diarrhea in the past two weeks: given more to eat", and "Household has a car". Other indicators that had most of their pairs within $\pm 20 \%$ were "Household treats drinking water" and "Ever married". All the indicators with the smallest differences between estimates had very low or very high prevalence (Table 6), except for "Consumption of vitamin A-rich foods" (that was based on only four pairs of estimates).

Table 7 summarizes the absolute differences between DHS/MICS and NGO, and between DHS and DHS. They are summarized according to the similarity of data collection timing (year and season), geographical level, and sample size. Using the absolute difference enabled us to see the size of the difference without taking the direction into account. The absolute difference between DHS/MICS and NGO estimates increases as year difference increases, as geographical levels difference increase, and as sample sizes decrease. The differences between DHS and DHS show similar patterns in terms of broad geographical level, sample size, and $\geq 3.5$ years versus 0 to 3 years' time differences.

Table 8 shows the partition of variation results from DHS/MICS vs NGO and DHS vs DHS comparison. For DHS/MICS vs NGO about $15 \%$ of the variance was attributed to the indicator and less than $1 \%$ attributed to geographical level, year and season difference. For DHS vs DHS, geographical level and year account for more variation in absolute difference (1.25 and $4.5 \%$ respectively). However, in all cases, most $(>82 \%)$ of the variance was unattributed, that is, it remained unexplained by the model.

Results from all three comparisons, DHS/MICS - NGO, DHS - DHS, and Simulations, are shown in Figure 3 as boxplots of the absolute difference between estimates by the indicator reference value (the DHS estimate or the estimate simulating DHS). The distribution of absolute differences is similar between DHS/MICS - NGO and DHS - DHS, with DHS/MICS NGO showing only a slightly larger spread. For all three types of comparisons, the distribution of the absolute difference between estimates is narrower in the extremes and larger when the reference value is between $35 \%$ and $65 \%$. Since the simulated sampling error differences are small (range $<10 \%$ ), only a small proportion of the differences can be attributed to sampling error.

\section{Discussion}

Our study showed that many indicators presented large differences between NGO and DHS/MICS estimates. Almost all indicators had at least some pairs that were widely different. Only about 33\% of the pairs of indicators were within 5\%, and about $80 \%$ of the pairs of indicators were within $20 \%$. Agreement between indicators was higher when comparing indicators that had low or high prevalence (e.g. $<15 \%$ or $>85 \%$ ), which is consistent with sampling theory, but throughout the prevalence range, the distribution of differences in the DHS/MICS-NGO and DHS-DHS comparisons is larger than that found from sampling error alone (reflected in the simulation distribution). An NGO could obtain an accurate estimate using DHS/MICS data for indicators with expected values close to $0 \%$ or $100 \%$.

We had hoped that if DHS/MICS and NGO estimates were similar, then NGOs could forego baseline data collection and use as a substitute DHS/MICS estimates, or estimates from some other publicly available dataset instead, saving NGO time and money, and reducing respondent burden. While we cannot give a blanket recommendation that DHS and MICS 
Table 6. DHS/MICS and NGO estimates, difference between estimates (DHS/MICS minus NGO) and proportion of estimates within $5 \%$ and $20 \%$ difference by subgroup of indicators.

\begin{tabular}{|c|c|c|c|c|c|c|c|c|c|c|c|}
\hline \multirow[b]{2}{*}{ Subgroup } & \multirow[b]{2}{*}{$\mathbf{N}$} & \multicolumn{2}{|c|}{$\begin{array}{l}\text { DHS/MICS } \\
\text { estimate }\end{array}$} & \multicolumn{2}{|c|}{$\begin{array}{l}\text { NGO } \\
\text { estimate }\end{array}$} & \multicolumn{4}{|c|}{$\begin{array}{l}\text { Difference between } \\
\text { estimates }\end{array}$} & \multicolumn{2}{|c|}{$\begin{array}{l}\text { Percentage } \\
\text { of indicator } \\
\text { pairs with } \\
\text { difference } \\
\text { within: }\end{array}$} \\
\hline & & Mean & SD & Mean & SD & Mean & SD & Min & Max & $5 \%$ & $20 \%$ \\
\hline \multicolumn{12}{|c|}{ Child anthropometry } \\
\hline Stunting (\%) & 131 & 30.6 & 10.4 & 36.4 & 11.9 & -5.7 & 9.8 & -42.1 & 20.6 & 38.2 & 93.1 \\
\hline $\begin{array}{l}\text { Underweight } \\
(\%)\end{array}$ & 131 & 26.9 & 12.8 & 18.5 & 8.7 & 8.5 & 11.1 & -15.2 & 32.3 & 30.5 & 80.9 \\
\hline \multicolumn{12}{|l|}{ Child diet } \\
\hline $\begin{array}{l}\text { Ate } 4+\text { food } \\
\text { groups (\%) }\end{array}$ & 67 & 21.3 & 9.2 & 22.6 & 12.3 & -1.3 & 12.3 & -23.2 & 28.9 & 25.4 & 94.0 \\
\hline $\begin{array}{l}\text { Bottle fed } \\
\text { yesterday (\%) }\end{array}$ & 33 & 8.8 & 6.4 & 6.9 & 9.4 & 1.9 & 6.8 & -20.8 & 13.1 & 63.6 & 97.0 \\
\hline $\begin{array}{l}\text { Consumption } \\
\text { of iron-rich } \\
\text { foods (\%) }\end{array}$ & 30 & 28.0 & 12.2 & 18.6 & 15.5 & 9.4 & 19.0 & -39.2 & 52.3 & 10.0 & 70.0 \\
\hline $\begin{array}{l}\text { Consumption } \\
\text { of vit A-rich } \\
\text { foods (\%) }\end{array}$ & 4 & 30.8 & 25.1 & 19.1 & 24.5 & 11.7 & 3.6 & 7.7 & 16.1 & 0.0 & 100.0 \\
\hline $\begin{array}{l}\text { Continued } \\
\text { breastfeeding } \\
\text { (\%) }\end{array}$ & 32 & 82.6 & 16.8 & 79.0 & 22.2 & 3.6 & 10.3 & -10.8 & 32.4 & 53.1 & 90.6 \\
\hline $\begin{array}{l}\text { Exclusive } \\
\text { breastfeeding: } \\
0-6 \mathrm{~m}(\%)\end{array}$ & 60 & 42.0 & 17.4 & 62.1 & 20.0 & -20.1 & 20.2 & -60.1 & 22.2 & 16.7 & 46.7 \\
\hline $\begin{array}{l}\text { Initiation of } \\
\text { breastfeeding } \\
\text { within } 1 \text { hour of } \\
\text { birth }(\%)\end{array}$ & 64 & 67.6 & 17.0 & 59.0 & 18.4 & 8.6 & 18.7 & -33.5 & 55.2 & 35.9 & 75.0 \\
\hline $\begin{array}{l}\text { Receiving } \\
\text { foods: } \\
\text { 6-8 m (\%) }\end{array}$ & 18 & 69.8 & 18.2 & 66.1 & 23.2 & 3.7 & 30.3 & -53.4 & 50.6 & 16.7 & 44.4 \\
\hline \multicolumn{12}{|l|}{ Child health } \\
\hline $\begin{array}{l}\text { Child received } \\
\text { supplement/ } \\
\text { vaccine (\%) }\end{array}$ & 10 & 57.6 & 21.7 & 65.7 & 25.8 & -8.1 & 15.7 & -37.9 & 14.6 & 20.0 & 80.0 \\
\hline $\begin{array}{l}\text { Diarrhea in the } \\
\text { last two weeks } \\
\text { (\%) }\end{array}$ & 86 & 19.1 & 9.4 & 30.7 & 20.2 & -11.6 & 14.5 & -46.8 & 15.8 & 33.7 & 70.9 \\
\hline $\begin{array}{l}\text { Diarrhea in the } \\
\text { last two weeks: } \\
0-5 \mathrm{~m}(\%)\end{array}$ & 11 & 9.8 & 7.0 & 14.9 & 7.8 & -5.1 & 3.7 & -10.4 & 2.8 & 54.5 & 100.0 \\
\hline $\begin{array}{l}\text { Diarrhea } \\
\text { treatment (\%) }\end{array}$ & 31 & 36.0 & 24.3 & 41.7 & 17.8 & -5.6 & 22.9 & -50.5 & 55.5 & 19.4 & 61.3 \\
\hline $\begin{array}{l}\text { Diarrhea, given } \\
\text { more to drink } \\
\text { (\%) }\end{array}$ & 22 & 19.3 & 10.7 & 27.0 & 16.8 & -7.7 & 21.4 & -52.3 & 30.1 & 13.6 & 63.6 \\
\hline $\begin{array}{l}\text { Diarrhea, given } \\
\text { more to eat (\%) }\end{array}$ & 14 & 8.8 & 4.4 & 6.8 & 4.9 & 2.0 & 3.9 & -6.0 & 7.9 & 64.3 & 100.0 \\
\hline \multicolumn{12}{|c|}{ Household characteristics } \\
\hline $\begin{array}{l}\text { Ever married } \\
(\%)\end{array}$ & 57 & 96.5 & 9.6 & 85.8 & 14.5 & 10.8 & 10.3 & -5.0 & 31.7 & 42.1 & 77.2 \\
\hline
\end{tabular}




\begin{tabular}{|c|c|c|c|c|c|c|c|c|c|c|c|}
\hline \multirow[b]{2}{*}{ Subgroup } & \multirow[b]{2}{*}{$\mathbf{N}$} & \multicolumn{2}{|c|}{$\begin{array}{l}\text { DHS/MICS } \\
\text { estimate }\end{array}$} & \multicolumn{2}{|c|}{$\begin{array}{l}\text { NGO } \\
\text { estimate }\end{array}$} & \multicolumn{4}{|c|}{$\begin{array}{l}\text { Difference between } \\
\text { estimates }\end{array}$} & \multicolumn{2}{|c|}{$\begin{array}{l}\text { Percentage } \\
\text { of indicator } \\
\text { pairs with } \\
\text { difference } \\
\text { within: }\end{array}$} \\
\hline & & Mean & SD & Mean & SD & Mean & SD & Min & Max & $5 \%$ & $20 \%$ \\
\hline $\begin{array}{l}\text { Household has } \\
\text { electricity (\%) }\end{array}$ & 20 & 43.8 & 40.6 & 44.6 & 38.8 & -0.8 & 9.2 & -21.9 & 15.4 & 60.0 & 95.0 \\
\hline $\begin{array}{l}\text { Head of } \\
\text { household is } \\
\text { male (\%) }\end{array}$ & 78 & 85.6 & 11.6 & 87.9 & 8.4 & -2.3 & 8.8 & -25.3 & 25.8 & 56.4 & 92.3 \\
\hline $\begin{array}{l}\text { Urban } \\
\text { residence (\%) }\end{array}$ & 12 & 23.0 & 11.9 & 31.8 & 11.8 & -8.8 & 15.5 & -36.3 & 12.2 & 33.3 & 75.0 \\
\hline \multicolumn{12}{|c|}{ Household wealth } \\
\hline $\begin{array}{l}\text { Household has } \\
\text { a car (\%) }\end{array}$ & 46 & 2.0 & 2.4 & 1.8 & 3.9 & 0.2 & 2.7 & -12.4 & 5.3 & 91.3 & 100.0 \\
\hline $\begin{array}{l}\text { Household has } \\
\text { agricultural } \\
\text { land/bike/ } \\
\text { phone (\%) }\end{array}$ & 150 & 56.1 & 28.4 & 50.5 & 29.5 & 5.7 & 14.4 & -52.9 & 41.7 & 34.7 & 82.7 \\
\hline $\begin{array}{l}\text { Household has } \\
\text { animals (\%) }\end{array}$ & 73 & 41.9 & 25.3 & 37.9 & 23.2 & 4.0 & 9.5 & -24.0 & 29.5 & 41.1 & 93.2 \\
\hline \multicolumn{12}{|c|}{ Maternal characteristics/health } \\
\hline $\begin{array}{l}\text { Woman able to } \\
\text { read (\%) }\end{array}$ & 8 & 33.2 & 22.9 & 27.3 & 14.6 & 5.9 & 11.4 & -6.4 & 21.0 & 12.5 & 87.5 \\
\hline $\begin{array}{l}\text { Woman never } \\
\text { attended } \\
\text { school (\%) }\end{array}$ & 58 & 40.3 & 29.9 & 36.5 & 28.5 & 3.8 & 12.5 & -43.7 & 53.1 & 37.9 & 94.8 \\
\hline $\begin{array}{l}\text { Birth at a } \\
\text { health facility/ } \\
\text { assisted by } \\
\text { skilled birth } \\
\text { attendant (\%) }\end{array}$ & 127 & 46.5 & 22.7 & 59.1 & 24.0 & -12.6 & 15.6 & -45.0 & 49.0 & 17.3 & 69.3 \\
\hline $\begin{array}{l}\text { Woman } \\
\text { received/ } \\
\text { consumed iron } \\
\text { supplements } \\
\text { (\%) }\end{array}$ & 63 & 49.7 & 28.4 & 49.8 & 32.8 & -0.2 & 17.8 & -38.0 & 55.5 & 33.3 & 76.2 \\
\hline $\begin{array}{l}\text { Woman } \\
\text { received } \\
\text { antenatal care } \\
(\%)\end{array}$ & 162 & 58.2 & 24.5 & 63.2 & 23.7 & -5.0 & 16.1 & -35.7 & 54.6 & 24.1 & 75.3 \\
\hline $\begin{array}{l}\text { Woman } \\
\text { received } \\
\text { postnatal care } \\
(\%)\end{array}$ & 51 & 41.6 & 17.1 & 44.0 & 23.6 & -2.4 & 29.2 & -65.6 & 78.0 & 5.9 & 51.0 \\
\hline $\begin{array}{l}\text { Woman's ANC } \\
\text { content (\%) }\end{array}$ & 56 & 55.3 & 21.4 & 57.2 & 26.2 & -1.9 & 27.6 & -60.9 & 46.4 & 14.3 & 48.2 \\
\hline \multicolumn{12}{|l|}{ WASH } \\
\hline $\begin{array}{l}\text { Household } \\
\text { dispose child } \\
\text { stool in toilet/ } \\
\text { latrine (\%) }\end{array}$ & 14 & 55.9 & 27.5 & 65.4 & 26.8 & -9.5 & 14.8 & -38.7 & 20.3 & 28.6 & 78.6 \\
\hline $\begin{array}{l}\text { Household has } \\
\text { improved } \\
\text { drinking water } \\
\text { (\%) }\end{array}$ & 87 & 64.5 & 26.8 & 70.3 & 24.2 & -5.7 & 17.2 & -54.6 & 51.9 & 34.5 & 81.6 \\
\hline
\end{tabular}




\begin{tabular}{|c|c|c|c|c|c|c|c|c|c|c|c|}
\hline \multirow[b]{2}{*}{ Subgroup } & \multirow[b]{2}{*}{$\mathbf{N}$} & \multicolumn{2}{|c|}{$\begin{array}{l}\text { DHS/MICS } \\
\text { estimate }\end{array}$} & \multicolumn{2}{|c|}{$\begin{array}{l}\text { NGO } \\
\text { estimate }\end{array}$} & \multicolumn{4}{|c|}{$\begin{array}{l}\text { Difference between } \\
\text { estimates }\end{array}$} & \multicolumn{2}{|c|}{$\begin{array}{l}\text { Percentage } \\
\text { of indicator } \\
\text { pairs with } \\
\text { difference } \\
\text { within: }\end{array}$} \\
\hline & & Mean & SD & Mean & SD & Mean & SD & Min & Max & $5 \%$ & $20 \%$ \\
\hline $\begin{array}{l}\text { Household has } \\
\text { improved } \\
\text { sanitation (\%) }\end{array}$ & 82 & 33.5 & 21.4 & 40.8 & 27.8 & -7.3 & 26.8 & -62.4 & 77.5 & 12.2 & 53.7 \\
\hline $\begin{array}{l}\text { Household } \\
\text { shares toilet } \\
(\%)\end{array}$ & 11 & 31.7 & 13.9 & 28.5 & 13.7 & 3.2 & 18.0 & -21.2 & 47.7 & 27.3 & 81.8 \\
\hline $\begin{array}{l}\text { Household } \\
\text { treats drinking } \\
\text { water (\%) }\end{array}$ & 52 & 8.4 & 8.7 & 15.2 & 14.1 & -6.8 & 15.4 & -50.8 & 19.1 & 53.8 & 86.5 \\
\hline $\begin{array}{l}\text { Handwash } \\
\text { station has } \\
\text { ash/sand/ } \\
\text { soap/water (\%) }\end{array}$ & 25 & 20.8 & 12.5 & 30.5 & 21.5 & -9.8 & 16.8 & -57.8 & 26.6 & 24.0 & 76.0 \\
\hline $\begin{array}{l}\text { Time to obtain } \\
\text { drinking water } \\
30+\min (\%)\end{array}$ & 20 & 33.4 & 12.1 & 36.1 & 20.2 & -2.7 & 22.8 & -46.2 & 58.3 & 25.0 & 75.0 \\
\hline
\end{tabular}

DHS: Demographic and Health Surveys; MICS: Multiple Indicator Cluster Surveys; NGO: non-governmental organization; SD: standard deviation; ANC: antenatal care; WASH: Water, Sanitation and Hygiene.

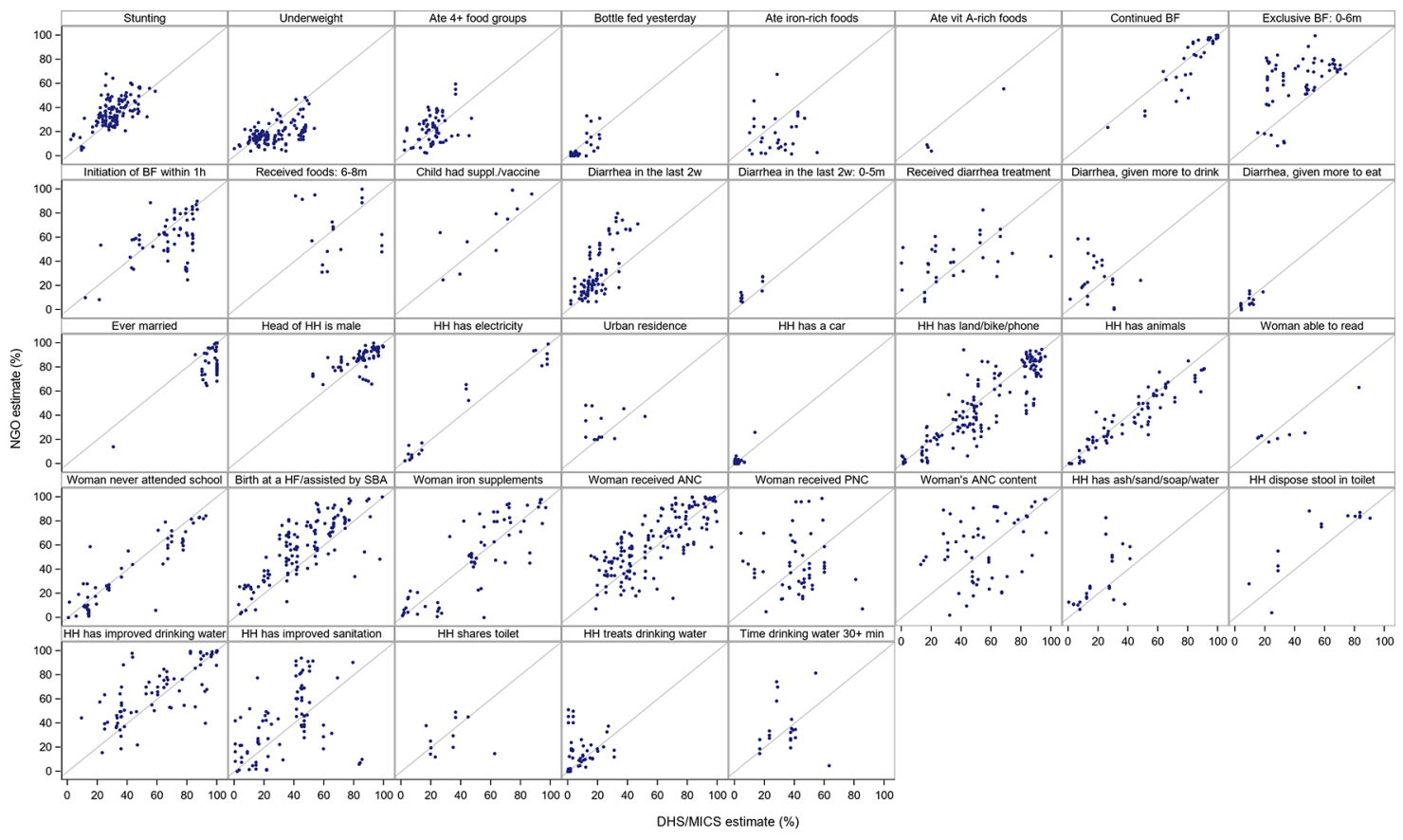

Figure 1. DHS/MICS estimate by NGO estimate by subgroup of indicators. Abbreviations: BF: breastfeeding; $\mathrm{HH}$ : household; HF: health facility; SBA: skilled birth attendant; ANC: antenatal care; PNC: postnatal care; DHS: Demographic and Health Surveys; MICS: Multiple Indicator Cluster Surveys; NGO: non-governmental organization.

could always replace NGO baseline surveys, there are at least some situations where DHS/MICS could be used to the NGO's advantage: when the estimate is expected to be less than $15 \%$ or above $85 \%$; when the indicator of interest is one of the few with consistent similarity between DHS/MICS and NGO estimates; and when the NGO has tolerance for estimates of low or unknown accuracy. 


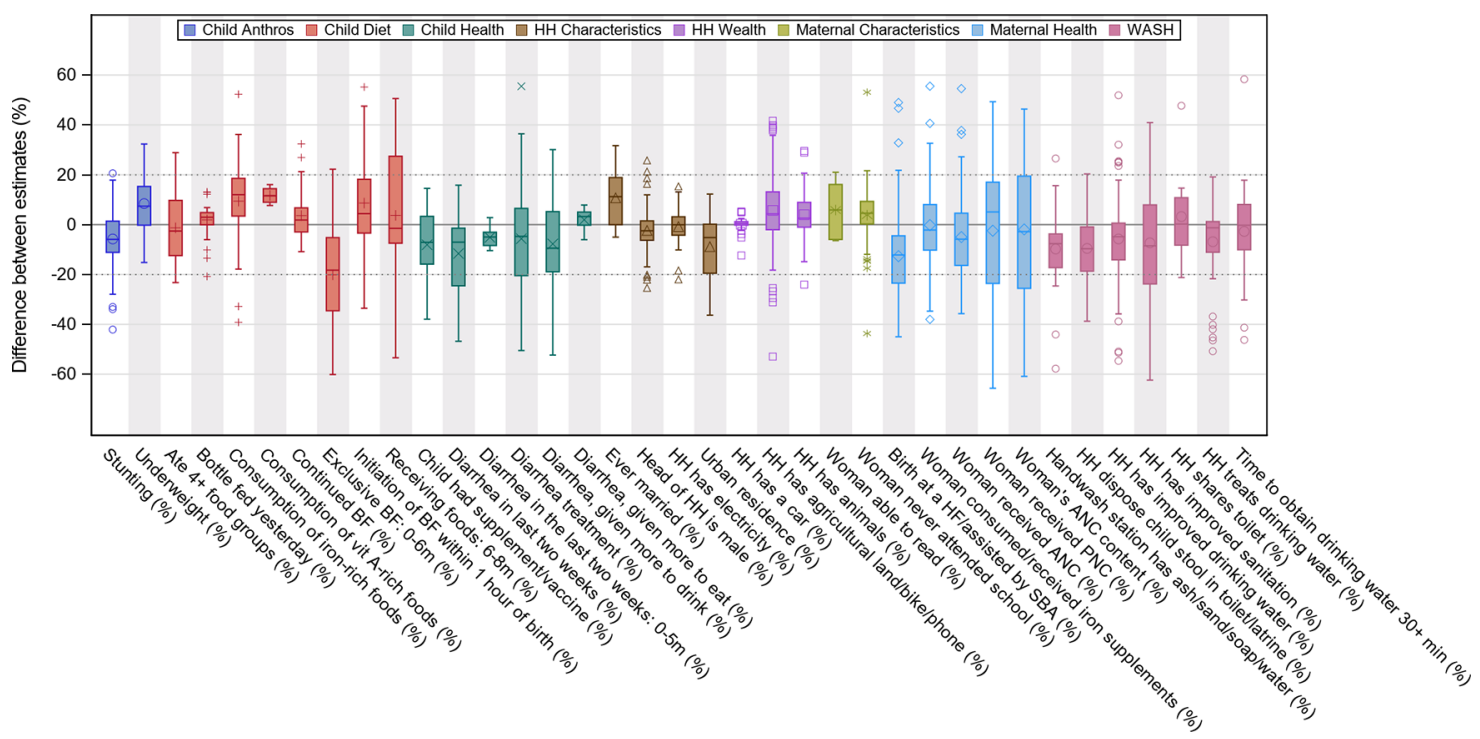

Figure 2. Difference between estimates (DHS/MICS minus NGO) by subgroup of indicators. Abbreviations: Anthros: anthropometry indicators; HH: household; WASH: Water, Sanitation, and Hygiene; BF: breastfeeding; HF: health facility; SBA: skilled birth attendant; ANC: antenatal care; PNC: postnatal care; DHS: Demographic and Health Surveys; MICS: Multiple Indicator Cluster Surveys; NGO: non-governmental organization.

We had hypothesized that publicly available data can provide estimates of baseline conditions similar to those reported in NGO baseline reports when matched as closely as possible for location, year, and season of data collection. From the descriptive analyses, we found that as year difference increased, the mean difference between estimates slightly increased, and estimates derived from lower geographical levels (such as village or district from NGO and province for DHS/MICS) contributed to a higher mean absolute difference between estimates. In general, larger sample sizes were obtained at higher geographical levels and the larger the sample size (with their smaller sampling error) from DHS/MICS or NGO, the smaller the mean absolute difference between estimates. This meant that the advantage of geographical proximity is offset by the larger sampling error associated with small sample sizes. Whether the seasons of data collection were matched or different did not make a measurable difference to the similarity between estimates.

However, the partition of variance analyses showed that DHS/MICS and NGO estimates differed, for the most part, in unpredictable ways, and geographical levels, years difference and seasons explained only a small part of the variation.

We hypothesize that large differences between estimates from NGO baseline reports and DHS/MICS data are due to three main reasons:

(i) It is possible that NGOs' estimates are collected from different populations with different underlying true values. NGOs often try to target lower wealth villages, and so baseline estimates may be worse off than the nationally representative DHS/MICS estimates. Note, however, that differences in household wealth indicators were small (e.g. "Household has electricity" $0.8 \%$ difference; "Household has a car" $0.2 \%$ difference). Additionally, the differences between DHS/MICS and NGO estimates might reflect actual changes over the years or across different geographical locations. Results from the analyses comparing data from the same source (DHS) but from different years and geographical levels also resulted in large differences between estimates.

(ii) Different methods employed while sampling, collecting, processing and analyzing data might also have contributed to the differences between DHS/MICS and NGO estimates.

(iii) Several indicators related to maternal and child health included in this study have not been validated and some have been shown to have low validity, such as maternal report of skilled birth attendance (Blanc et al., 2016). Inappropriate conflation of answer options and inconsistent coding and analysis of DHS surveys has also been documented (Footman et al., 2015). High measurement error can result in bias in unpredictable direction and dimension, resulting in large differences between estimates. 
Table 7. Absolute difference of estimates by year difference, season, geographical level, and sample size.

\begin{tabular}{|c|c|c|c|c|c|c|c|c|c|c|}
\hline \multirow[b]{2}{*}{ Variable } & \multicolumn{5}{|c|}{ DHS/MICS vs NGO } & \multicolumn{5}{|c|}{ DHS vs DHS } \\
\hline & $\mathbf{N}$ & Mean & SD & Median & IQR & $\mathbf{N}$ & Mean & SD & Median & IQR \\
\hline \multicolumn{11}{|l|}{ Year difference } \\
\hline$\leq 1$ year & 495 & 11.6 & 10.4 & 9.2 & 12.6 & 56185 & 10.1 & 10.2 & 6.9 & 11.7 \\
\hline $1.5-3$ years & 860 & 12.8 & 12.8 & 8.4 & 15.9 & 8024 & 9.3 & 9.1 & 6.6 & 10.7 \\
\hline$\geq 3.5$ years & 641 & 13.8 & 13.2 & 10.1 & 15.1 & 45042 & 13.6 & 13.9 & 9.2 & 15.3 \\
\hline \multicolumn{11}{|l|}{ Season } \\
\hline Same season & 1153 & 13.1 & 12.8 & 9.0 & 14.4 & - & - & - & - & - \\
\hline Different season & 603 & 11.8 & 11.2 & 8.5 & 14.6 & - & - & - & - & - \\
\hline $\begin{array}{l}\text { Season } \\
\text { unknown }\end{array}$ & 240 & 14.2 & 13.0 & 10.3 & 16.2 & - & - & - & - & - \\
\hline \multicolumn{11}{|c|}{ Geographical level difference } \\
\hline 0 & 677 & 12.5 & 12.6 & 8.3 & 14.2 & 9024 & 10.1 & 11.5 & 6.2 & 11.4 \\
\hline 1 & 897 & 13.1 & 12.3 & 9.6 & 15.4 & 30275 & 10.5 & 10.9 & 7.1 & 11.9 \\
\hline $2+$ & 422 & 12.8 & 12.2 & 9.0 & 14.9 & 69952 & 12.1 & 12.4 & 8.2 & 13.8 \\
\hline \multicolumn{11}{|c|}{ Geographical level $1^{a, b}$} \\
\hline Country & 14 & 7.7 & 7.7 & 3.9 & 6.1 & 61230 & 11.9 & 12.2 & 8.1 & 13.7 \\
\hline Region & 1259 & 13.1 & 12.9 & 9.0 & 15.9 & 25248 & 10.9 & 12.2 & 7.0 & 12.0 \\
\hline Province & 723 & 12.4 & 11.4 & 9.3 & 13.4 & 22773 & 10.8 & 10.8 & 7.5 & 12.6 \\
\hline \multicolumn{11}{|c|}{ Geographical level $2^{c, d}$} \\
\hline Country & 14 & 7.7 & 7.7 & 3.9 & 6.1 & 896 & 7.0 & 8.7 & 3.9 & 7.2 \\
\hline Region & 369 & 12.6 & 12.2 & 8.7 & 14.2 & 8826 & 11.3 & 13.1 & 7.1 & 12.7 \\
\hline Province & 422 & 12.5 & 12.4 & 9.0 & 13.7 & 30875 & 9.1 & 9.7 & 5.9 & 10.1 \\
\hline District & 963 & 13.0 & 12.3 & 9.3 & 15.2 & 68654 & 12.6 & 12.6 & 8.8 & 14.5 \\
\hline Village & 228 & 13.5 & 13.3 & 8.6 & 17.6 & - & - & - & - & - \\
\hline \multicolumn{11}{|l|}{ Sample size $1^{\mathrm{a}, \mathrm{b}}$} \\
\hline $\begin{array}{l}\text { Tertile } 1\left(n^{a}=335\right. \\
\left.n^{b}=709\right)\end{array}$ & 663 & 14.1 & 13.1 & 9.8 & 16.6 & 36418 & 11.5 & 12.1 & 7.8 & 12.6 \\
\hline Tertile 2 & 656 & 12.9 & 12.4 & 9.3 & 15.0 & 36695 & 11.2 & 11.7 & 7.5 & 12.9 \\
\hline $\begin{array}{l}\text { Tertile } 3\left(n^{a}=772,\right. \\
\left.n^{b}=5282\right)\end{array}$ & 677 & 11.6 & 11.5 & 8.2 & 13.3 & 36138 & 11.7 & 12.1 & 7.8 & 13.8 \\
\hline \multicolumn{11}{|l|}{ Sample size $2^{c, d}$} \\
\hline $\begin{array}{l}\text { Tertile } 1 \quad\left(n^{c}=236\right. \\
\left.n^{d}=37\right)\end{array}$ & 664 & 14.8 & 13.7 & 10.4 & 17.5 & 36480 & 13.7 & 13.0 & 10.0 & 14.9 \\
\hline Tertile 2 & 668 & 12.0 & 12.0 & 8.1 & 14.0 & 36407 & 11.7 & 11.9 & 8.0 & 13.1 \\
\hline $\begin{array}{l}\text { Tertile } 3\left(n^{c}=757\right. \\
\left.n^{d}=104\right)\end{array}$ & 664 & 11.7 & 11.1 & 8.7 & 13.4 & 36364 & 9.0 & 10.4 & 5.4 & 10.3 \\
\hline
\end{tabular}

${ }^{a}$ For the DHS/MICS - NGO comparison, refers to the DHS/MICS data.

${ }^{\mathrm{b}}$ For the DHS - DHS comparison, refers to the DHS data from the higher geographical level and earlier survey year.

${ }^{C}$ For the DHS/MICS - NGO comparison, refers to the NGO data.

${ }^{\mathrm{d}}$ For the DHS - DHS comparison, refers to the data mimicking the NGO (from the lower geographical level and more recent survey year).

DHS: Demographic and Health Surveys; MICS: Multiple Indicator Cluster Surveys; NGO: non-governmental organization.

Whatever the cause of the large differences between estimates was, it was not possible to know which of the data sources (DHS/MICS or NGO) provided the most accurate estimation of the true prevalence in the NGOs target populations. Furthermore, while we have been comparing DHS/MICS and NGO point estimates, these indicators are measured with 


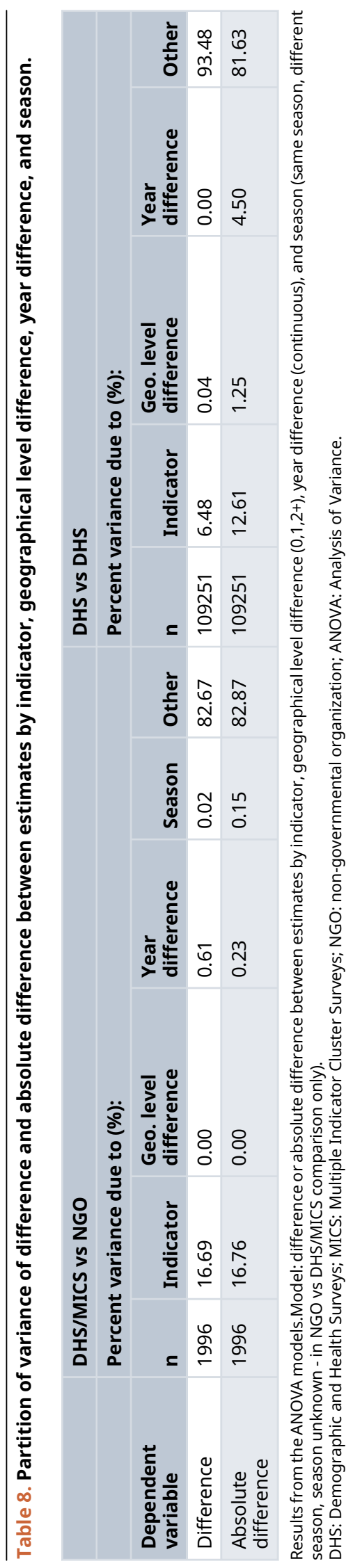




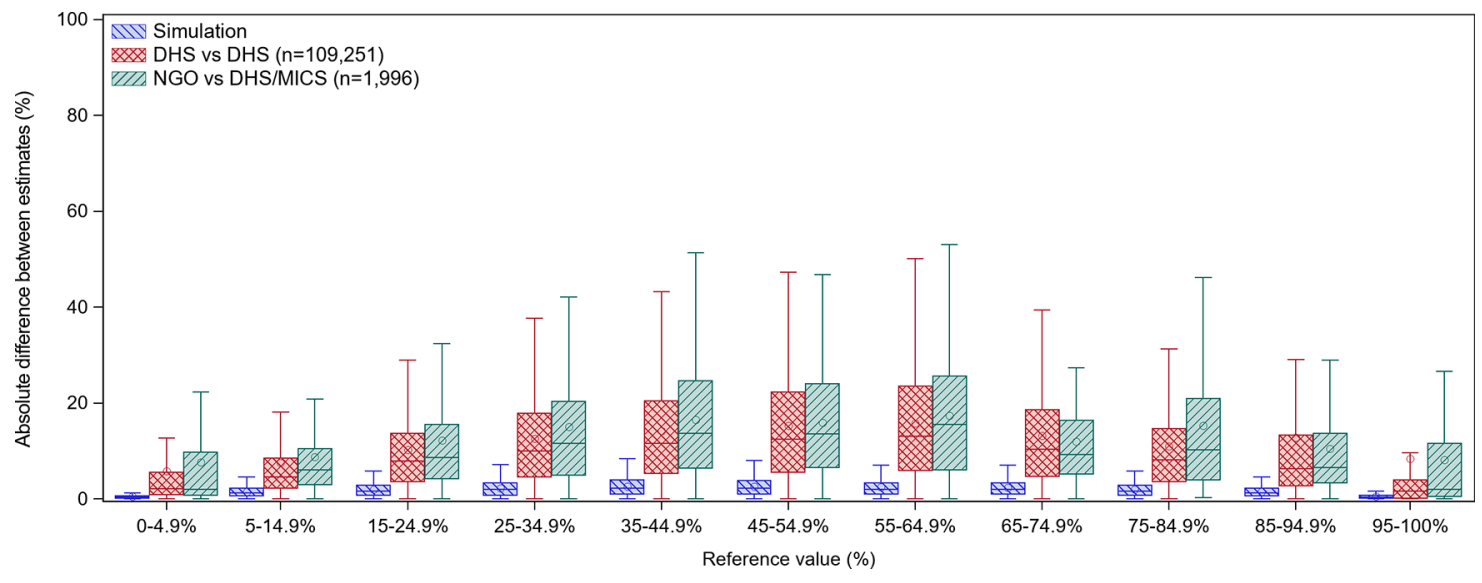

Figure 3. Box plot of absolute difference between NGO and DHS/MICS estimates by the reference value. Absolute difference between estimates calculated as:

Simulation: Simulated estimate 1 - Simulated estimate 2

DHS vs DHS: DHS estimate - DHS mimicking the NGO estimate (lower geographical level, more recent year of data collection)

DHS/MICS vs NGO: DHS/MICS estimate - NGO estimate

Reference value: DHS or the estimate mimicking DHS (higher geographical level, earlier year of data collection) Abbreviations: DHS: Demographic and Health Surveys; MICS: Multiple Indicator Cluster Surveys; NGO: nongovernmental organization.

error. The standard error (SE) for the DHS indicators is greater than 5\% in eleven percent of the estimates. An estimate with a standard error of $5 \%$ will have a $95 \%$ confidence interval of $\pm 9.8 \%$.

Our analyses document and try to understand the large differences between NGO and DHS/MICS estimates. However, a study comparing DHS data to a small population-based survey from Rwanda showed that nine out of fifteen indicators related to maternal, newborn and child health were within a 10\% difference (Langston et al., 2015). Similarly, in case studies from Nepal and Vietnam (HealthBridge, 2020) there were many indicators where the DHS/MICS and NGO estimates were similar. In Nepal $70 \%$ of indicators were within $20 \%$ of one another. Estimates for ANC, ironfolic acid uptake, vitamin A supplementation at 18-23 months and mobile ownership were similar while breastfeeding, child dietary diversity and tetanus vaccination in pregnancy differed widely. In contrast, in Vietnam NGO estimates for exclusive/continued breastfeeding and dietary diversity at 6-8 months were close to DHS, while others differed by $>30 \%$. Using secondary data may be useful, especially in situations of budget or mobility restraint, such as during the COVID-19 pandemic with limited data collection opportunities. However, use of DHS surveys may risk underestimating the scale of problems for poor and marginalised groups such as nomads or slum dwellers (Carr-Hill, 2017). When using DHS/MICS data, the user must keep in mind the potential differences between DHS/MICS and NGO estimates.

This study had some limitations. Most NGO data we used came from unpublished, not peer-reviewed reports created for internal use only. Indicators extracted from NGO reports were not necessarily consistent across all reports and often SDs or SEs were missing. Although, we matched the methods employed by the NGO as closely as possible in order to obtain the same indicators from DHS/MICS, some reports provided limited information concerning methods of data collection and analysis. Dates of and season of data collection were impossible to assess for eight reports. Assigning the geographical level of data from the NGO report was also challenging for some settings due to lack of contextual information. However, we were able to communicate with several NGOs in order to obtain supplementary information about the reports' methods.

\section{Conclusion}

Our hypothesis was that publicly available data can provide estimates of baseline conditions similar to those reported in NGO baseline reports when matched as closely as possible for location, year, and season of data collection. Our answer to this, in brief, is that publicly available data can be used, if the NGO is tolerant of imprecise estimates.

While an NGO may use the evidence presented here to justify forgoing their own baseline survey, they should keep in mind that DHS and MICS provide estimates for only some of the indicators of interest to the NGO. On average, we estimated 18 of the NGO's indicators using DHS/MICS, but NGOs were often reporting 100+ estimates. Furthermore, collecting data in the NGO working area can provide valuable insights for project design and implementation. 


\section{Data availability}

This study used data owned by the DHS, the MICS and the NGOs that shared their baseline report. The DHS data can be downloaded at: https://www.dhsprogram.com, and the MICS data can be obtained at: https://mics.unicef.org. The DHS and MICS require registration and data access are only granted for legitimate research purposes.

The NGO reports were either available online on each NGO website or obtained by personal contact by email. The full list of NGO reports used in this study including report title, year of publication, organization name and how to access each report can be found at:

Harvard Dataverse: Details on reports used in the Maxdata project. https://doi.org/10.7910/DVN/32FUQV (Berti, 2021).

Data are available under the terms of the Creative Commons Zero "No rights reserved" data waiver (CC0 1.0 Public domain dedication).

\section{Acknowledgements}

We thank all non-governmental organizations that shared their baseline reports with us, and USAID and UNICEF for making the Demographic and Health Surveys (DHS) and Multiple Indicator Cluster Surveys (MICS) data available. We thank Bana Salameh for assisting with extraction of data from the NGO reports.

\section{References}

Anoke SC, Mwai $P$, Jeffery $C$, et al: Comparing two survey methods of measuring health-related indicators: Lot Quality Assurance Sampling and Demographic Health Surveys. Trop Med Int Health 2015; 20(12):

1756-1770.

PubMed Abstract | Publisher Full Text

Berti P: Details on reports used in the Maxdata project. Harvard Dataverse 2021; V1.

Publisher Full Text

Blanc AK, Warren C, McCarthy KJ, et al.: Assessing the validity of indicators of the quality of maternal and newborn health care in Kenya.J Glob Health 2016; 6(1): 010405.

PubMed Abstract | Publisher Full Text | Free Full Text

Carr-Hill R: Missing Millions and Measuring Development Progress.

World Development 2013; 46(C): 30-44.

Publisher Full Text

Carr-Hill R: Improving Population and Poverty Estimates with Citizen Surveys: Evidence from East Africa. World Development 2017; 93: 249-259.

Publisher Full Text

Croft TN, Marshall AMJ, Allen CK: Guide to DHS Statistics 2018; ICF.

Data for Impact: Data for Impact: What's the cost of evaluations and other surveys? - MEASURE Evaluation 2019.

Reference Source

Footman K, Benova L, Goodman C, et al.: Using multi-country household surveys to understand who provides reproductive and maternal health services in low- and middle-income countries: A critical appraisal of the Demographic and Health Surveys. Trop Med Int Health 2015; 20(5): 589-606.

PubMed Abstract | Publisher Full Text | Free Full Text

Hancioglu A, Arnold F: Measuring Coverage in MNCH: Tracking

Progress in Health for Women and Children Using DHS and MICS

Household Surveys. PLoS Med 2013; 10(5): e1001391.

PubMed Abstract | Publisher Full Text | Free Full Text

HealthBridge: Final Report: Maximizing use of existing data to

strengthen program design, evaluation, and impact. HealthBridge; 2020. Reference Source

Langston AC, Prosnitz DM, Sarriot EG: Neglected value of

small population-based surveys: A comparison with

demographic and health survey data. J Health Popul Nutr 2015;

33(1): 123-136

PubMed Abstract | Free Full Text

UNICEF:About Multiple Indicator Cluster Surveys (MICS). 2020

Reference Source

U.S. Agency for International Development: The Demographic and Health Survey (DHS) Overview. 2018.

Reference Source

Wodon Q, Cong Nguyen M, Tsimpo C: Market share of faith-inspired and private secular health care providers in Africa: Comparing DHS and multi-

purpose integrated surveys. 2012

Reference Source 


\section{Open Peer Review}

\section{Current Peer Review Status:}

\section{Version 1}

Reviewer Report 24 May 2021

https://doi.org/10.5256/f1000research.50696.r78936

(C) 2021 Walker N. This is an open access peer review report distributed under the terms of the Creative Commons Attribution License, which permits unrestricted use, distribution, and reproduction in any medium, provided the original work is properly cited.

\section{Neff Walker}

Senior Scientist, Johns Hopkins Bloomberg School of Public Health, Baltimore, MD, USA

This paper addresses a very interesting question but I must admit I remain unconvinced that the analyses presented here actually answer the question raised. From my perspective and that of the authors, the answer to this question is primarily related to how representative the data from the big surveys are of the program population. So for me, at one level the answer to this question is rather straightforward. If an NGO is working at provincial level and there has been a recent (in the last year) DHS or MICS survey that was sampled to be representative at the provincial level, then I would always use the DHS and MICS data as the baseline data forgoing the data collection by the NGO. Not only does this save time and energy, but my bias is that I believe the methods (e.g., sample size, mapping and household listing for sampling) used by major surveys like DHS and MICS are almost better than what an NGO would use. Of course, the answer to this question becomes less clear as the DHS or MICS survey data become less representative of the ideal program baseline, either in time or population. This is in large part what the analyses presented in this paper were all about.

On the time issue, would I still use the DHS data if it was two years old? In large part the answer to that question depends on how rapidly the indicators you are measuring change. If, for example, one was interested in measuring baseline values such as total fertility rate, household composition, wealth which change very slowly two or even five year period between the survey and the start of the NGO program would not be a big concern. However, for indicators that may change quickly, say coverage of some interventions like bednet ownership, vitamin A supplementation coverage which can quickly be scaled up with campaigns, data from a survey that is two or more years old would probably not provide a very accurate measure. While the analyses presented here did some work to look at this issue I am not really sure that it was captured in their analyses.

On population representation, using data from a very recent DHS survey that is sampled to be representative at a provincial level as baseline data for a program that covers $80 \%$ of the province may be okay. The data are not perfectly representative but unless there is extreme heterogeneity in the indicators of interest using the indicator values from the province probably provide a 
reasonable estimate of baseline coverage and therefore could replace a separate NGO-run survey. As with time, the key is how much variability is there within the population that was sampled for the DHS or MICS survey. This is hard to know, but clearly urban rural differences, ethnic mixes, topology all link to this. Again, I would think this would be a major issue that again, am not sure is captured in the current analyses.

I think these are exactly the issues that the authors were seeking to address in their analyses so why do I feel like these results do not really help us much in finding the answer? In their analyses they matched DHS/MICS data to data from NGO's and then looked at how well these points matched when they varies in time or population. One major issue for me revolves around the NGO survey data. The analytical approach basically assumes that NGO surveys produced the right answer (as they are for the correct population and for the right time) ignoring that methodological or procedural weakness in the NGO surveys (e.g., lack of household listing, mapping during sampling, small sample size, poor training and supervision of interviewers) may make their results far from a gold standard comparison. I think I would be happier with analyses that restricted the comparisons to NGO surveys where a review of the methods and procedures and the sample size of the survey make me more confident about the quality of the NGO estimates.

The second issue I have is the inclusion of data from DHS and MICS surveys that is broken down into smaller geographic region that was part of the sampling frame. Even if there are sufficient households at the district level, I am left wondering why we would expect the data to be very representative if that was not part of the sampling frame. I suppose that was part of the authors point of the analyses, but then we were not surprised that we found very weak correspondence between estimates of variables at the smaller geographic areas. I am a bit surprised the authors did not build a bit more on previous work on small area estimation that has tried to address many of the same issues focusing not just on differences due to population differences but also on techniques to adjust for these.

Is the work clearly and accurately presented and does it cite the current literature? Partly

Is the study design appropriate and is the work technically sound? Partly

Are sufficient details of methods and analysis provided to allow replication by others? Yes

If applicable, is the statistical analysis and its interpretation appropriate? Yes

Are all the source data underlying the results available to ensure full reproducibility? Yes

Are the conclusions drawn adequately supported by the results? Yes

Competing Interests: No competing interests were disclosed. 
Reviewer Expertise: Modeling, program evaluation, estimation procedures

\section{I confirm that I have read this submission and believe that I have an appropriate level of expertise to confirm that it is of an acceptable scientific standard.}

Author Response 18 Aug 2021

Peter Berti, HealthBridge Foundation of Canada, Ottawa, Canada

We thank the reviewer for these helpful comments. We agree with much of what the reviewer has offered, and we provide some clarification to other points.

The reviewer observed that "The analytical approach basically assumes that NGO surveys produced the right answer". Thanks for pointing this out. In earlier versions of the paper we were careful to note that we do not consider either the NGO or DHS/MICS to be "right". We do not consider either the NGO estimates or the DHS/MICS estimates to be correct. Rather, the NGOs have used their reported estimates to characterize the baseline conditions and we are testing if they would have had similar characterization if they used the existing publically available data.

Whether the NGO is "right" or not, those are the baseline estimates that they have used. For the scope of this study, we did not test if they were right or if DHS/MICS was right, but rather, would they have the same, or similar, baseline estimates if they used DHS/MICS.

We agree that if we could isolate those NGO baseline surveys that used stronger methods and better trained teams would have lower measurement error, and so would be more similar to the DHS/MICS estimates. However, our research question was intended to address all NGO baseline reports, to determine if, in general, there was concordance between the estimates. Also, note that most of the NGOs were well resourced, international NGOs (see Table 1). We did test for an "NGO effect" but there was no observable impact of NGO on the concordance. Note also that we compared DHS to DHS estimates in different geographical levels and years and the absolute differences were similar to the ones observed when comparing DHS/MICS vs NGO (see Figure 3).

We had a similar hypothesis to the reviewer. We expected that when the time between surveys was shorter, concordance would be higher. We also expected that some indicators would be much more concordant than others. However, our intuition was not consistent with the results, where we observed that most of the variation between estimates was not due to timing nor the indicator, but rather to unattributed error.

We also expected that a closer match in location would have higher concordance, but again, this is not what we observed.

Competing Interests: No competing interests were disclosed. 


\section{https://doi.org/10.5256/f1000research.50696.r78933}

(c) 2021 Basil L. This is an open access peer review report distributed under the terms of the Creative Commons Attribution License, which permits unrestricted use, distribution, and reproduction in any medium, provided the original work is properly cited.

\section{Luay Basil}

Canadian Red Cross Society, Ottawa, ON, Canada

The paper addresses an important issue tackled frequently by NGOs that struggle to decide whether to use existing data or collect their own at baseline. It follows a rigorous methodology and uses a good number of studies to draw conclusions from. Thank you for the excellent work. Below are some reflections, questions and suggestions.

\section{Introduction:}

Statement in $\mathrm{p} 3$ "In addition, the accuracy of the indicator estimates in NGO-led surveys may be insufficient for project design and monitoring purposes, due to relatively small sample sizes and the inherent high variability of the indicators of interest."

Since the statement is in the introduction section, and since the paper shows later that sampling errors are not a factor for the studies that met the criteria of inclusion, how do we reconcile between both?

A sample size of NGOs might be adequate for indicators such as antenatal care, postnatal care, delivery by skilled birth attendant, but not for illnesses among children under 5 years when we ask about children with symptoms in the past 2 weeks or when measuring the prevalence of early child marriage among adolescents since the age group is between 14 and 17, especially if the focus is on girls. Have such indicators been part of the simulations to see the potential errors by NGOs in sampling? Can the paper mention whether sample size by NGOs is a factor in such cases? Are such indicators the one that are in the small error of sampling in Figure 3? If so, would it be better for NGOs to use DHS/MICS data even when the surveys are a few years old or for a higher level of geography compared to their areas?

In addition to the challenges in sample size, sometimes the questionnaire in NGOs' baseline surveys are not technically sound to measure a standard indicator. Has this been observed from the cases reviewed? If so, the paper could refer to that and add suggest using the questionnaire of DHS/MICS if the NGO is going to collect its own baseline data, especially

\section{Table 4:} since they are adjusted to local context.

Scenario 1 shows improvement for a geography over time but there is not much difference within the provinces or geographies in the same year.

Scenario 2 shows there is not much difference between 3rd level and national level in the same survey.

Scenario 3 shows estimates of a later study that is not much different from earlier (slight improvement) because the earlier performance was quite high at $88.5 \%$.

Question: The table illustrate an important point; to what level is it representative of all examined studies? It would be good to mention that. If it is not representative, could the paper cite another example where there are significant differences? Or, at least mention that there is, if this is the case. See related comment on Table 4 later. 


\section{Table 6:}

Is there a need to explain in the methodology the rationale behind selecting $5 \%$ and $20 \%$ as the thresholds for comparison of differences? What would the picture be if the thresholds were $10 \%$ and $20 \%$ ?

\section{Discussion:}

P19 statement "In general, larger sample sizes were obtained at higher geographical levels and the larger the sample size (with their smaller sampling error) from DHS/MICS or NGO, the smaller the mean absolute difference between estimates. This meant that the advantage of geographical proximity is offset by the larger sampling error associated with small sample sizes." One would expect that the NGO would calculate the adequate sample size required using a sample calculator (like the one of RADAR project). If the resources available would result in a sample size that is significantly less than the adequate one, should there be a recommendation that the NGO uses DHS/MICS data?

P19 statement "It is possible that NGOs' estimates are collected from different populations with different underlying true values. NGOs often try to target lower wealth villages, and so baseline estimates may be worse off than the nationally representative DHS/MICS estimates. Note, however, that differences in household wealth indicators were small (e.g. "Household has electricity" 0.8\% difference; "Household has a car" 0.2\% difference)." Since the DHS presents some findings by wealth quintiles, one would expect that findings from the lowest quintile could represent the areas NGOs work in and be close to those from NGOs data. Was comparison between indicators values from NGOs and the lowest wealth quintile from DHS made? If so, could you add a statement to reflect that?

P 19 statement "Additionally, the differences between DHS/MICS and NGO estimates might reflect actual changes over the years or across different geographical locations. Results from the analyses comparing data from the same source (DHS) but from different years and geographical levels also resulted in large differences between estimates." Table 4 for Zambia does not show large differences. Are there other studies that have that?

\section{Conclusions:}

P 22 "Our hypothesis was that publicly available data can provide estimates of baseline conditions similar to those reported in NGO baseline reports when matched as closely as possible for location, year, and season of data collection. Our answer to this, in brief, is that publicly available data can be used, if the NGO is tolerant of imprecise estimates." The paper also shows that NGO can use DHS/MICS when the values of the indicators are very high or very low.

P 22 statement "While an NGO may use the evidence presented here to justify forgoing their own baseline survey, they should keep in mind that DHS and MICS provide estimates for only some of the indicators of interest to the NGO. On average, we estimated 18 of the NGO's indicators using DHS/MICS, but NGOs were often reporting 100+ estimates. Furthermore, collecting data in the NGO working area can provide valuable insights for project design and implementation." It would be good to expand on this in the discussion section. NGOs' need to measure different outcome levels on knowledge, attitudes and practice; the first two guide project design, implementation and setting targets. NGOs also need to report on the different outcome levels to their donors. DHS/MICS focus more on practice/utilization of services and less on attitude and knowledge. 


\section{Additional point}

In a webinar presenting the paper in March 2, 2021, it was mentioned if an NGO wants to have a baseline so it can compare with the end-line, it can have a properly randomized and controlled end-line that can give good findings on the project's impact. Could that be added to the paper?

Is the work clearly and accurately presented and does it cite the current literature? Yes

Is the study design appropriate and is the work technically sound? Yes

Are sufficient details of methods and analysis provided to allow replication by others? Yes

If applicable, is the statistical analysis and its interpretation appropriate? I cannot comment. A qualified statistician is required.

Are all the source data underlying the results available to ensure full reproducibility? Yes

Are the conclusions drawn adequately supported by the results? Yes

Competing Interests: No competing interests were disclosed.

Reviewer Expertise: I have been involved in several baseline and end-line surveys for projects in pubic health conducted in developing countries and have witnessed the pros and cons of conducting them. My engagement has been in the planning, design, data analysis and reporting phases. I have also used findings from the DHS/MICS to guide project design, implementation and evaluation.

I confirm that I have read this submission and believe that I have an appropriate level of expertise to confirm that it is of an acceptable scientific standard.

Author Response 18 Aug 2021

Peter Berti, HealthBridge Foundation of Canada, Ottawa, Canada

Thank you very much for taking the time to review our manuscript and for these detailed and thoughtful comments. Please see below the answers to your comments.

\section{Introduction}

Comment 1: Statement in $p 3$ "In addition, the accuracy of the indicator estimates in NGO-led surveys may be insufficient for project design and monitoring purposes, due to relatively small sample sizes and the inherent high variability of the indicators of interest." Since the statement is 
in the introduction section, and since the paper shows later that sampling errors are not a factor for the studies that met the criteria of inclusion, how do we reconcile between both?

Answer to Comment 1: Thanks for this comment. In the paper we show that the larger the sample size the smaller the difference between estimates (Table 7). However, we note that the advantages of larger sample size are often offset by being drawn from a higher geographical area, and so for an NGO working at the village level, they provide less specific information about the target village.

Comment 2: A sample size of NGOs might be adequate for indicators such as antenatal care, postnatal care, delivery by skilled birth attendant, but not for illnesses among children under 5 years when we ask about children with symptoms in the past 2 weeks or when measuring the prevalence of early child marriage among adolescents since the age group is between 14 and 17, especially if the focus is on girls. Have such indicators been part of the simulations to see the potential errors by NGOs in sampling? Can the paper mention whether sample size by NGOs is a factor in such cases? Are such indicators the one that are in the small error of sampling in Figure 3? If so, would it be better for NGOs to use DHS/MICS data even when the surveys are a few years old or for a higher level of geography compared to their areas?

Answer to Comment 2: As you note, sample size for a household survey is largest for household level indicators, smaller for populations that are subsets of households (such as children under 5 years) and smaller still for subsets of those subsets (such as children who have been ill in the past two weeks). Sampling error is inversely proportional to sample size and this relationship would hold across all indicators. There is nothing unique about those indicators, other than their smaller sample size. That said, a quick analysis shows that for those indicators that are drawn from subpopulations (in most cases regarding children who have had diarrhea in the previous two weeks), agreement between DHS/MICS and NGO estimates is somewhat lower, with only $65 \%$ of estimates falling within $+/-20$ percentage points of each other

Comment 3: In addition to the challenges in sample size, sometimes the questionnaire in NGOs' baseline surveys are not technically sound to measure a standard indicator. Has this been observed from the cases reviewed? If so, the paper could refer to that and add suggest using the questionnaire of DHS/MICS if the NGO is going to collect its own baseline data, especially since they are adjusted to local context.

Answer to Comment 3: We did not review the NGO reports for technical quality. However, in our experience, NGOs are usually quite good at finding and using recommended, validated tools when such tools exist. Often there is no single recommended, validated method though and this can result in differences in estimates. We addressed this in the discussion in points ii and iii.

Comment 4: Table 4: Scenario 1 shows improvement for a geography over time but there is not much difference within the provinces or geographies in the same year.

Scenario 2 shows there is not much difference between 3 rd level and national level in the same survey. Scenario 3 shows estimates of a later study that is not much different from earlier (slight improvement) because the earlier performance was quite high at $88.5 \%$.

Question: The table illustrate an important point; to what level is it representative of all examined 
studies? It would be good to mention that. If it is not representative, could the paper cite another example where there are significant differences? Or, at least mention that there is, if this is the case. See related comment on Table 4 later.

Answer to Comment 4: Note that Table 4 is just to show an example of how the calculations were done for the three scenarios. It is just for one indicator, so should not be over interpreted. It is not meant to be representative. We used ANC for the example because it is one of the most commonly reported indicators. For the meaning of the results, the reader should refer to the full report. However, we realized after reading your comment that we have neglected to report on the three different scenarios. While it is documented in the full report, the results of the three scenarios are not very different so we reported the three scenarios combined, which is the most similar to the DHS/MICS - NGO comparisons.

Comment 5: Table 6: Is there a need to explain in the methodology the rationale behind selecting $5 \%$ and $20 \%$ as the thresholds for comparison of differences? What would the picture be if the thresholds were $10 \%$ and $20 \%$ ?

Answer to Comment 6: Those levels were arbitrarily chosen as very good (5\%) and fair (20\%) agreement. Because the differences are on a continuum, the cut-off of $10 \%$ yields, as you would expect, values between those for 5 and $20 \%$. We in fact did this for the report (Table 4 in HealthBridge, 2020) (also for 15\%) but we did not include it in this shorter paper.

\section{Discussion}

Comment 6: P19 statement "In general, larger sample sizes were obtained at higher geographical levels and the larger the sample size (with their smaller sampling error) from DHS/MICS or NGO, the smaller the mean absolute difference between estimates. This meant that the advantage of geographical proximity is offset by the larger sampling error associated with small sample sizes." One would expect that the NGO would calculate the adequate sample size required using a sample calculator (like the one of RADAR project). If the resources available would result in a sample size that is significantly less than the adequate one, should there be a recommendation that the NGO uses DHS/MICS data?

Answer to Comment 6: That is a good point and we agree with you.

Comment 7: P19 statement "It is possible that NGOs' estimates are collected from different populations with different underlying true values. NGOs often try to target lower wealth villages, and so baseline estimates may be worse off than the nationally representative DHS/MICS estimates. Note, however, that differences in household wealth indicators were small (e.g. "Household has electricity" $0.8 \%$ difference; "Household has a car" $0.2 \%$ difference)." Since the DHS presents some findings by wealth quintiles, one would expect that findings from the lowest quintile could represent the areas NGOs work in and be close to those from NGOs data. Was comparison between indicators values from NGOs and the lowest wealth quintile from DHS made? If so, could you add a statement to reflect that?

Answer to Comment 7: That is another good point, thanks for your comment, but unfortunately, we did not do so. We will hopefully have the opportunity to address this question in future studies.

Comment 8: P 19 statement "Additionally, the differences between DHS/MICS and NGO estimates 
might reflect actual changes over the years or across different geographical locations. Results from the analyses comparing data from the same source (DHS) but from different years and geographical levels also resulted in large differences between estimates." Table 4 for Zambia does not show large differences. Are there other studies that have that?

Answer to Comment 8: Table 4 is just an example. There were 9,024 matches in Scenario 1 (comparing the same indicator in the same geographical level at two points in time). Yes, some of these show apparent improvements, and some show apparent worsening, but part of the point is that these real secular changes may well be artifacts of method/sampling/random error.

\section{Conclusions}

Comment 9: P 22 "Our hypothesis was that publicly available data can provide estimates of baseline conditions similar to those reported in NGO baseline reports when matched as closely as possible for location, year, and season of data collection. Our answer to this, in brief, is that publicly available data can be used, if the NGO is tolerant of imprecise estimates." The paper also shows that NGO can use DHS/MICS when the values of the indicators are very high or very low.

Answer to Comment 9: We agree with you.

Comment 10: $P 22$ statement "While an NGO may use the evidence presented here to justify forgoing their own baseline survey, they should keep in mind that DHS and MICS provide estimates for only some of the indicators of interest to the NGO. On average, we estimated 18 of the NGO's indicators using DHS/MICS, but NGOs were often reporting 100+ estimates. Furthermore, collecting data in the NGO working area can provide valuable insights for project design and implementation." It would be good to expand on this in the discussion section. NGOs' need to measure different outcome levels on knowledge, attitudes and practice; the first two guide project design, implementation and setting targets. NGOs also need to report on the different outcome levels to their donors. DHS/MICS focus more on practice/utilization of services and less on attitude and knowledge.

Answer to Comment 10: That is a very useful added detail. Thank you.

\section{Additional point}

Comment 11: In a webinar presenting the paper in March 2, 2021, it was mentioned if an NGO wants to have a baseline so it can compare with the end-line, it can have a properly randomized and controlled end-line that can give good findings on the project's impact. Could that be added to the paper?

Answer to Comment 11: We had that point in earlier versions but then felt it was too different from the main point of the paper. We are adding in here links to two blogs and a paper that we were drawing on when we made this point. By including it here, interested readers will be able to find it.

1. Alaka Holla, Are we over-investing in baselines?

https://blogs.worldbank.org/impactevaluations/are-we-over-investing-baselines

2. David Evans, Advice for impact evaluations with government: Drop the baseline.

https://davidevans.blog/2018/06/21/advice-for-impact-evaluations-with-government-dropthe-baseline/ 
3. McKenzie D (2012) Beyond baseline and follow-up: The case for more $T$ in experiments. Journal of Development Economics. 99(2):210-221 http://datacolada.org/wp-content/uploads/2015/06/5191-McKenzie-JDE-2012-Beyondbaseline-and-follow-up-the-case-for-more-t-in-experiments.pdf

In a similar vein, I have put the links below to two papers on "shoestring evaluations". 1. Bamberger M, Rugh J, Church M (2004) Shoestring Evaluation: Designing Impact Evaluations under Budget, Time and Data. Am J Evaluation 25(1): 5-37 http://www.managingforimpact.org/sites/default/files/resource/shoestring_evaluation.pdf 2. Can we trust shoestring evaluations? Martin Ravallion, 2013 http://documents.worldbank.org/curated/en/604591468332054439/pdf/WPS5983.pdf

Competing Interests: No competing interests were disclosed.

The benefits of publishing with F1000Research:

- Your article is published within days, with no editorial bias

- You can publish traditional articles, null/negative results, case reports, data notes and more

- The peer review process is transparent and collaborative

- Your article is indexed in PubMed after passing peer review

- Dedicated customer support at every stage

For pre-submission enquiries, contact research@f1000.com 